\title{
LA «JORNADA REAL» DE CATALUNYA QUE PROPICIÓ LA CAÍDA DEL CONDE DUQUE DE OLIVARES
}

\author{
ANTONI SIMON I TARRÉS \\ Universitat Autònoma de Barcelona \\ Institut d'Estudis Catalans
}

Fecha de recepción: octubre de 2009. Fecha de aceptación: enero de 2010.

La «jornada» emprendida por Felipe IV el 26 de abril de 1642 para recobrar Catalunya, finalizó, el 6 de diciembre de ese mismo año, cuando el monarca y su válido retornaron a Madrid, procedentes de Zaragoza, con un balance lleno de frustraciones y derrotas. El naufragio político y militar de esa campaña ha sido interpretado como un elemento clave en la caída política del conde duque de Olivares. Gregorio Marañón subrayó que al regresar Felipe IV a la capital de la monarquía, el «pleito del conde duque estaba fallado». ${ }^{1}$ También, para J.H. Elliott, el fracaso de la expedición real en el frente catalán "selló el destino del conde duque». ${ }^{2}$ Una campaña militar ignominiosa había dañado seriamente la reputación del monarca y Olivares era considerado el principal «responsable» de ello. ${ }^{3}$ Es cierto que para explicar la caída del todopoderoso valido de Felipe IV no se puede obviar la oposición manifestada por gran parte de la aristocracia hacia las formas de gobierno impuestas por el conde duque, ni tampoco las maniobras cortesanas para derribarlo. Asimismo, no cabe olvidar el marco social de descontento derivado del estado de postración que vivía el pueblo castellano, el cual era duramente castigado por las alteraciones de la moneda de vellón. Sin embargo, tal como el mismo Olivares manifestaba a finales de 1642 a Pierre Rosse, si el rey hubiese

\footnotetext{
1. MARAÑón, Gregorio: El conde-duque de Olivares. La pasión de mandar, Madrid, 1980 (primera edición de 1936), la cita en p. 347.

2. ElliotT, John H.: Richelieu y Olivares, Barcelona, 1984, p. 200.

3. Idem., El conde-duque de Olivares. El político en una época de decadencia, Barcelona, 1990, p. 619.
} 
regresado de Aragón «con la gloria que se entendía», ${ }^{4}$ ello, indudablemente, además de hacer remontar la reputación real, hubiese reforzado la posición política del valido.

De la campaña real de Catalunya se han explorado básicamente los ecos y percepciones que tuvo en el mundo político de la época; ${ }^{5}$ en cambio, muy poco se ha dicho sobre la estrategia político-militar en que se sustentó. ${ }^{6}$ Este tema es, a nuestro entender, fundamental para comprender las razones del fracaso de la jornada real y, consiguientemente, de la defenestración política de Olivares. El análisis de dicha estrategia político-militar tiene una especial relevancia porqué, tal como demostraremos en este artículo -y contra lo que no en pocas veces se ha afirmado- la jornada real de Catalunya fue impulsada y diseñada por el propio conde duque de Olivares y las juntas que el controlaba -la de Ejecución y la Junta Grande-, y, por tanto, el fracaso de la campaña lógicamente tenía que repercutir en su posición política.

\section{LA ESTRATEGIA POLÍTICA Y MILITAR PARA RECUPERAR CATALUNYA DESPUÉS DEL TRIUNFO DE TARRAGONA (AGOSTO DE 1641). LOS RIESGOS DE LA EUFORIA OLIVARISTA}

Después de la dolorosa derrota del marqués de Los Vélez en la batalla de Montjuïc (26 de enero de 1641) y de la posterior retirada del ejército real a la plaza de Tarragona, la prioridad militar del gobierno de Madrid se centró en salvar la antigua Tarraco del asedio que por tierra y por mar la sometieron las tropas francocatalanas del mariscal La Mothe y los navíos del almirante Henri de Sourdis, arzobispo de Burdeos. ${ }^{7}$ Cuando el 20 de agosto de 1641 la armada española dirigida por el marqués de Villafranca y el duque de Maqueda rompió el bloqueo marítimo, consiguió hacer entrar refuerzos y víveres al puerto de Tarragona y, a la vez, puso en fuga a la flota francesa, el gran enojo con que Richelieu recibió la noticia, ${ }^{8}$ era inversamente proporcional al alivio y satisfacción obtenidos por Olivares y Felipe IV. Los habitantes de la villa y corte madrileña celebraron la buena nueva del triunfo de Tarragona con hogueras, luminarias y otros regocijos, los cuales fueron acompañados por el repique de las campanas de las iglesias y, según testimonia José Pellicer en sus Avisos, «salió el señor conde duque i luego la señora condesa de Olivares a dar gracias a todos los santuarios e imágenes de

4. Ibid., citado en p. 619.

5. Ibid., p. 602 ss.

6. Los aspectos militares han sido tratados recientemente en la tesis doctoral inédita de CAMARERO, Raquel: La Guerra de Recuperación de Cataluña 1640-1652, Universidad de Valladolid, 2007, especialmente en los epígrafes: «La estrategia después de Tarragona» y «La desastrosa campaña de 1642», p. 214-386. Esta investigación, paralela a la nuestra, ha compartido la documentación del Archivo General de Simancas.

7. Sobre el asedio de Tarragona, básicamente: SANABRE, Josep: La acción de Francia en Cataluña en la pugna por la hegemonía de Europa 1640-1659, Barcelona, 1956, p. 156 ss.; GüELL, Manel : El setge de Tarragona de 1641, Tarragona, 2003; y la documentación publicada por PUJOL y CAMPS, C.: Memorial Histórico Español (MHE), vol. XXV, Madrid, 1893, apéndice XXVII, p. 676-720.

8. Ver SANABRE, Josep : La acción de Francia...(1956), p 162 s. 
devoción, dentro y fuera de Madrid». ${ }^{9}$ Con los bríos proporcionados por aquel triunfo militar que, además de asegurar Tarragona, daba a los españoles el domino de la costa catalana, el día 28 de agosto la Junta de Ejecución, con Olivares al frente, se reunió para representar al rey lo que «convendría disponer para la continuación de la guerra de Cataluña». ${ }^{10}$ Los miembros de la junta elevaron a Felipe IV una propuesta estratégica que se concretaba en los diecisiete puntos siguientes:

1. En primer lugar, con el providencialismo característico de la corte madrileña, la junta abogaba por continuar las oraciones y plegarias públicas que se venían realizando para el buen desenlace de la guerra, pues «será de gran fruto tener de nuestra parte a Nuestro Señor».

2. Se proponía mantener abiertas las puertas a la negociación por «si quisieran gozar de la piedad [del rey] los catalanes»».

3. Se consideraba que la principal prioridad militar era socorrer las plazas del Rosselló aún en manos españolas y que eran sitiadas por el ejército francocatalán, ello debía hacerse «de manera que por ningún casso se atrase su cumplimiento».

4. Asimismo, se consideraba «inexcusable» la toma de los puertos de Cadaquès y Palamós.

5. Para hacer posibles todos estos planes militares, especialmente el socorro de las plazas del Rosselló, se proponía ajustar asientos con los hombres de negocios.

6. La junta también decía que la salida del rey al frente «como en otras ocasiones se ha considerado puede ser parte para mejorar las cosas pendientes», y demandaba al monarca que fijase en el plazo de un mes o poco más tiempo el día para su salida, y que también designase para el efecto una plaza de armas, Guadalajara o bien Ocaña.

7. La junta, a continuación, realizaba diversas previsiones militares para el frente de Catalunya. Se proponía dejar en plaza de Tarragona una guarnición de 2.000 infantes y 800 caballos, el resto de las fuerzas allí concentradas se destinarían a la empresa de la conquista de Lleida, donde convergerían con las tropas ya disponibles en Fraga y las que se reclutarían con la salida de Felipe IV al frente catalán.

8. Se dejaría en Tortosa una guarnición de 1.500 infantes y 500 caballos, destinando igualmente el sobrante a la empresa de Lleida.

9. Con ello, antes de la llegada real, se calculaba que frente a la ciudad del Segre ya estarían concentrados 8.000 infantes y 2.500 caballos.

10. Se enviarían bastimentos y vituallas a las plazas del Rosselló para asegurarlas por el tiempo de un año, quedando en ellas 4.000 infantes de guarnición.

11. En Roses y en las proyectadas conquistas de los puertos de Cadaquès y Palamós se destinarían 3.000 infantes. Además, Roses contaría con 800 caballos, la misma cifra que también cubriría las plazas del Rosselló.

9. Pellicer y Tovar, José: Avisos, edición y notas de Jean Claude Chevalier y Lucien Clare, Paris, 2 vols., 2002-2003, la cita en vol. I, p. 276.

10. Archivo General de Simancas (AGS), Guerra Antigua, 1377, Junta de Ejecución de 28 de agosto de 1641. 
12. Con estas fuerzas ya distribuidas, habría que acudir «a lo demás», según las circunstancias de cada momento.

13. Se interpretaba que con esta dispersión de fuerzas se causaría gran daño a los francocatalanes, «pues se berán obligados a tener gente en todas partes».

14. Los miembros de la Junta de Ejecución apuntaban también la conveniencia de conquistar la plaza de Cervera, ello con el objetivo de «apretar» a Barcelona y dar «la mano» con Tortosa.

15. Muy confiados en las capacidades militares y económicas de la Corona, Olivares y los miembros de la junta proponían que las fuerzas sobrantes de infantería y caballería fuesen aplicadas a la guerra de Portugal.

16. Igualmente, en otra previsión optimista, preveían que si la costa de Catalunya quedase libre de la amenaza de la escuadra francesa, sólo se mantuviese una flota de 8 o 10 galeras reforzada con algunos navíos y pataches.

17. Finalmente, la junta proponía que el Consejo de Aragón tomase medidas para asegurar el buen gobierno político y el funcionamiento de la justicia en Tarragona, ello con el objetivo de propiciar el retorno de los habitantes que se habían ausentado de la ciudad a causa de las operaciones militares.

Por indicación de Felipe IV, las propuestas de la Junta de Ejecución fueron tratadas en la Junta Grande, la cual se reunió al completo el día 1 de septiembre. ${ }^{11}$ La Junta Grande ratificó las medidas estratégicas diseñadas por la de Ejecución, pero Olivares introdujo a debate la interrogación de «si convendría apretar las negociaciones de Cataluña llamando o esperando que los naturales la deseasen y usasen de algún expediente»; es decir, planteaba la cuestión de tomar, o no, la iniciativa en una posible negociación con los catalanes. Los miembros de la junta no dudaban de la prioridad que representaba resolver las «cosas» de Catalunya, "pues no solamente arrastran tras sí las de Portugal sino otras consecuencias grabísimas de la monarquía», pero sólo veían factible y recomendable la negociación desde una posición de fuerza y superioridad militar; por tanto, proponían a Felipe IV que se activasen los preparativos bélicos previstos por la Junta de Ejecución: «porqué proposiciones ni diligencias con el cuerpo de la Provincia no parecía tiempo [...] por lo qual sería bien se apretase la ejecución de lo resuelto en materia de guerra pues esto daría calor y facilitaría nuestras negociaciones». Felipe IV no solamente dio el visto bueno a la propuesta si no que ordenó «la ejecución de todo sin ninguna discusión».

La vía de una solución negociada con los catalanes no era nueva $\mathrm{y}$, de hecho durante el año 1640 y los primeros meses de 1641 ya habían existido diversas oportunidades para un acuerdo. Especialmente intensos habían sido los intentos de mediación del papa Urbano VIII y del nuncio apostólico monseñor Fachinetti, ${ }^{12}$ pero la intransigencia de la corte madrileña había abortado las posibilidades de aquellos puentes tendidos. Según opinaba a comienzos de septiembre de 1641 el embajador toscano

11. AGS, Guerra Antigua, 1377, Junta Grande de 1 de septiembre de 1641.

12. Cfr. SANABRE, Josep: La acción de Francia...(1956), p. 166 ss. 
Octavio Pucci, hasta aquella fecha Olivares había tenido varias ocasiones de llegar a un acuerdo ventajoso que salvase la reputación del rey, pero sus anhelos de quedar como un vencedor indiscutible del desafio lanzado por los catalanes había hecho que ninguna de esas oportunidades prosperase. ${ }^{13}$

Conviene decir que Olivares no estaba solo, ni mucho menos, en su actitud; de hecho aún existían posicionamientos más radicales al respecto. Hombres como el marqués de Villafranca estaban totalmente en contra de cualquier opción que no fuese la sujeción de Catalunya por la vía de las armas. A comienzos de 1641, cuando la sublevación de Portugal primero, y la derrota de Montjuïc después, hicieron que la corte de Madrid se plantease la vía negociadora con los catalanes, García Álvarez de Toledo y Osorio se manifestó frontalmente en contra de una solución negociada. En dos cartasmemorial de 16 de enero y 11 de febrero de 1641, Villafranca con un lenguaje duro y directo había defendido que la única respuesta que merecía la rebelión de los catalanes era un castigo «a palos», proponiendo que, una vez conquistado el Principado, se construyese una ciudadela en Barcelona y otros cuatro presidios en Lleida, Girona, Tarragona i Tortosa. ${ }^{14}$

Ahora, en septiembre de 1641, al volver a llegar a sus oídos que las juntas de la monarquía debatían de nuevo la posibilidad de una opción negociadora, Villafranca envió otra carta memorial al rey en que le representaba «lo mucho que conviene domar aquella provincia sujetándola desta vez para perpetua obediencia de V. Majestad». ${ }^{15}$

En su largo escrito, el marqués de Villafranca aportaba, en primer lugar, un plan militar para que con «medianas fuerzas» se recuperase Catalunya y se evitase cualquier pacto o cesión política. Su esbozo estratégico pasaba por dominar el mar y realizar simultáneamente diversas ofensivas terrestres: desde Tortosa y Tarragona se asaltaría el valioso coll de Balaguer con 3.000 infantes y 1.500 caballos; también desde Flix i Llerdacans entrarían 1.500 infantes y 500 caballos; a las puertas de Lleida la ofensiva se iniciaría con 4.000 infantes y 2.000 caballos; mientras que desde el condado de la Ribagorza se atacaría con 2.000 infantes y 1.000 caballos. Todas estas fuerzas convergerían para conquistar Bellpuig y Cervera, y después avanzarían hacia Barcelona que también sería sitiada por la armada real.

Según Villafranca la vía militar era la única posible para asegurar el dominio del rey sobre una provincia que llevaba en sus genes la perfidia de la rebeldía. Para García Álvarez de Osorio, el régimen de libertades había hecho de los catalanes unos vasallos insolentes y, a su parecer, sólo con la fuerza de las armas y una férrea sujeción posterior era posible enderezar aquel estado de cosas. Dando rienda suelta a sus sentimientos de animadversión, Villafranca manifestaba a Felipe IV que:

13. Cfr., Elliott, John H.: El conde duque...(1990), p. 621.

14. He publicado y analizado estas cartas del marqués de Villafranca en «Catalunya o Portugal? El dilema dels dos fronts i el marquès de Villafranca» en VALSALOBRe, Pep y SANSANO, Gabriel: (Eds.): Francesc Fontanella: una obra, una vida, un temps, Bellcaire d'Empordà, 2006, p. 13-42.

15. AGS, Guerra Antigua, 1377, el marqués de Villafranca al rey. 
«V. Majestad se ha de persuadir que Cataluña no ha de venir bien en ningún partido aunque sea muy en su provecho, porqué la fiereza de su naturaleza es incapaz de reducirse por beneficios y clemencia, y no creen cosa ninguna de lo que se les propone por parte de V. Majestad. Y dado caso que en esta ocasión se aprovecharan de la benignidad de V. Majestad, mañana volvieran a cometer los mismos delictos [...] Esta provincia, Señor ha sido la que en todas las ocasiones a desabrido a los reales progenitores de V. Majestad, y en todas las que se han ofrecido de disgusto y desabrimientos con ella, en lugar de castigar y quitarle los privilegios de que tanto blasonan y han abussado dellos, han usado con ella [ la provincia] de misericordia y clemencia, con que se han hecho insolentes y sobervios. Y pues tan justa causa han dado a V. Majestad para castigarlos y subyugarlos importará que V. Majestad se cuide, si puede, de su real clemencia, poniéndoles en Barcelona un castillo hecho a su costa para que sea continua memoria de su trayción y levantamiento, y para qué, de aquí adelante, no quiten obediencia con tanta facilidad a su Rey y Señor natural. Quíteles V. Majestad todos los privilegios, que si algún tiempo los merecieron como fieles vasallos de sus reyes, agora los han perdido con su inobediencia y rebelión voluntaria. Ponga V. Majestad en libertad la justicia, que no tiene V. Majestad provincia donde más graves y enormes delictos se cometen y menos se castigue que en Cataluña».

Aunque Olivares mantuviera una conocida animosidad contra el marqués de Villafranca y el linaje de los Toledo, ${ }^{16}$ ello no era obstáculo para que el conde duque compartiese, respecto a Catalunya, la mayor parte de los juicios de aquel altivo noble «nacido y criado para el mando» según caracterización que hizo de él Francisco Manuel de Melo. ${ }^{17}$ Cuando en enero de 1641 los marqueses de Mirabel y Castrofuerte propusieron la destrucción - para no dejar rastro histórico- de la primera carta-memorial que Villafranca había enviado al rey defendiendo la sujeción militar de Catalunya, Olivares se opuso afirmando que lo que decía la misiva era como «un evangelio». ${ }^{18}$

Ahora, a finales del verano de 1641, el conde duque acariciaba la ocasión de que un triunfo militar contundente liquidase aquel movimiento rebelde que tanto daño había hecho a la reputación de la Corona y a la suya propia. Por estas razones -y en contra de lo que han afirmado no pocos historiadores- fue el todopoderoso privado del rey quien relanzó el proyecto de una «jornada real» en Catalunya. Estas ambiciones que proyectaban una expedición victoriosa, coincidían plenamente con las de un Felipe IV ansioso si no de emular las grandes gestas de Carlos V, si, al menos, la que protagonizó Felipe II el 1591 reduciendo con autoridad militar y política las alteraciones de Aragón.

Sin embargo, como en otras muchas ocasiones, la euforia del momento había llevado a Olivares a una iniciativa precipitada, de la cual no había calculado los riesgos que conllevaba. En los meses siguientes las circunstancias militares, políticas y financieras, evidenciaron que las condiciones no eran nada favorables para una «jor-

16. Un apunte biográfico sobre el marqués de Villafranca en GüELL, Manel: El setge de...(2003), p. 69-72.

17. Melo, Francisco Manuel de: Historia de los movimientos, separación y guerra de Cataluña, Barcelona, edición de Seix Barral con título Guerra de Cataluña, 1969, p. 197

18. AGS, Guerra Antigua, 1331, Junta Grande de 26 de enero de 1641; ElLiOTT, John H.: La revolta catalana 1598-1640, Barcelona, 1966, p. 497. 
nada real» victoriosa en el frente catalán. Pero al lanzar la propuesta e involucrar tan directamente a Felipe IV en aquella jugada política y militar, el margen de rectificación del privado sería escaso.

\section{LOS PROBLEMAS LOGÍSTICOS Y FINANCIEROS DE LOS PLANES OLIVARISTAS}

La propuesta estratégica elaborada por la Junta de Ejecución del 28 de agosto de 1641 y ratificada por la Junta Grande y Felipe IV, se fue concretando en los meses siguientes con bastante más tardanza de lo que hubiese querido un ansioso Rey Planeta. Evidentemente era más fácil elaborar proyectos sobre el papel que conseguir recursos financieros y activar las capacidades logísticas necesarias para ejecutarlos.

A nivel marítimo, la Junta de Ejecución del 10 de septiembre propuso ordenar que las galeras del marqués de Villafranca acometiesen la expugnación de las plazas de Palamós y Cadaquès, considerando prioritaria la conquista de este último puerto, pues ello aseguraría el paso marítimo hacia Cotlliure y consecuentemente el abastecimiento de las fortalezas del Rosselló: «la importancia de asegurar a Cadaquès es de calidad que no se debe diferir ni dar lugar a que se dilate más de lo previsto». ${ }^{19}$ Quince días más tarde, la misma Junta de Ejecución preveía que diversas galeras de Italia fuesen enviadas a reforzar la armada que operaba en las costas de Catalunya, concretamente se disponía que dos galeras de Génova, dos de Cerdeña, tres de Nápoles y una de España, sirviesen en el Principado bajo el mando de Giannetino Doria. ${ }^{20}$ Sin embargo, ni Palamós ni Cadaquès fueron conquistadas por los españoles. El marqués de Villafranca alegando el mal estado de sus galeras se negó a salir a luchar contra la escuadra francesa y, a comienzos de 1642, ya estaba abiertamente enfrentado a Olivares, quien finalmente castigó su desobediencia con el arresto, primero en Denia y después en Odón. ${ }^{21}$ Tampoco corrió mejor suerte Giannetino Doria, quien, tal como veremos más adelante, fue capturado por los catalanes en febrero de 1642.

Los planes de la campaña terrestre que inmediatamente había de encabezar Felipe IV fueron pospuestos por razones financieras. Al no llegar la flota de la plata de Nueva España, ${ }^{22}$ el 25 de septiembre la Junta Grande dio marcha atrás a su resolución tomada hacía tan sólo tres semanas, aconsejando al monarca posponer la «jornada real» de Catalunya. Los miembros de la junta ahora consideraban que «en lo que mira a señalar día fijo para la salida de V. Majestad es dificultoso, porqué estas materias están sujetas a muchos accidentes y así es necesario caminar como el tiempo fuere aconsejando»; ese «tiempo» dependía fundamentalmente de la capacidad de la Corona para cerrar los

19. AGS, Guerra Antigua, 1337, Junta de Ejecución de 10 de septiembre de 1641.

20. AGS, Guerra Antigua, 1337, Junta de Ejecución de 25 de septiembre de 1641.

21. Ver GüELL, Manel: El setge de Tarragona... (2003), p. 71.

22. Sobre el retraso de la flota y la pérdida posterior de gran parte de ella, así como sobre las repercusiones que ello tuvo para la hacienda real y los hombres de negocios, ver ÁlvAREZ NoGAL, Carlos: El crédito de la monarquía hispánica en el reinado de Felipe IV, Valladolid, 1997, p. 103 s. 
asientos necesarios para financiar la campaña: «el movimiento de todo pende de las seguras probisiones de dinero, siendo cierto que es inexcusable que sean de qualidad que no falten en la mayor necesidad». Con la intención de aplacar a un impaciente Felipe IV, la Junta Grande trataba de rebajar las expectativas que ella misma había levantado hacia tan solo unas semanas. De la que tenía que ser una inmediata y triunfal jornada real en Catalunya, ahora se decía que «el modo de guerra que se [h]a ajustado para Catalunya no es para sitio real sino para la defensiva e ir obrando lo que las ocasiones permitieren que el ir la Real Persona de V. Majestad para alentar y consolar a aquellos vasallos y no siendo sino para este effecto no es de esencia que sea en invierno o verano». Felipe IV no tuvo más remedio que aceptar la situación, escribiendo de su puño y letra en la consulta: «como parece, haciendo oraciones por la venida de la flota y galeones», pero añadiendo que «a los que tratan de los medios del asiento he mandado dar gran prissa». ${ }^{23}$

En aquellos momentos, Castilla vivía una aguda crisis monetaria. El 27 de octubre de 1641 una pragmática real dispuso resellar todo el vellón acuñado entre 1617 y 1626; esta medida leonina generó un alud de resellos falsificados, con lo cual la Real Hacienda no obtuvo los beneficios esperados y, en cambio, sí disparó los precios de las subsistencias y paralizó las transacciones comerciales. ${ }^{24} \mathrm{El}$ aumento del vellón y su depreciación subsiguiente se tradujo en un alza incontenible del premio de la plata que pasó del 52 por 100 el marzo del 1641 al 90 por 100 en el diciembre de ese mismo año. ${ }^{25}$ Así, los funcionarios de la hacienda real al no disponer de las remesas de la plata americana y tener que pagar un alto precio por ella en Castilla, tenían grandes dificultades para cerrar los contratos de los asientos de la proyectada jornada de Catalunya.

A pesar de estas graves dificultades financieras, Olivares no abandonó sus planes militares sobre Catalunya. El 6 de noviembre de 1641 presentó a la Junta Grande un «papel» en que se detallaban el número y la distribución de los efectivos a movilizar en la futura campaña. El conde duque confiaba en que la plata de las Indias que debía llegar la próxima primavera, le permitiría contar con una gran fuerza armada. En conjunto, preveía disponer de 1.500 caballos y 7.000 infantes en el Rosselló, así como de 24.500 infantes y 5.500 caballos entre Tarragona y Fraga; en su «papel», Olivares afirmaba convencido y confiado que todo lo resuelto «debe afixarse bien su cumplimiento para que no se ande en equivocaciones y para que V. Majestad, siendo Dios servido, quando vinieren la flota y los galeones y llegue allí su real persona se halle con exército digno della y de poder con él estar con toda dignidad y reputación». ${ }^{26}$ Como era de esperar, los miembros de la Junta Grande no sólo aprobaron la traza militar de Olivares, sino que recomendaron al rey que al conde-duque se le diesen «muy

23. AGS, Guerra Antigua, 1377, Junta Grande de 25 de septiembre de 1641.

24. Cfr., Domínguez OrTIZ, Antonio: Política y hacienda de Felipe IV, Madrid, 1960, p. 263.

25. Ibid., p. 59.

26. AGS, Guerra Antigua, 1377, Junta Grande de 6 de noviembre de 1641. 
particulares gracias» por el celo demostrado, disponiendo que de sus planes bélicos se hiciesen copias para los mandos y personas que debían ejecutarlos.

A finales de diciembre de 1641, Olivares aún confiaba en el éxito de la futura jornada real de Cataluña. Las noticias que llegaban a la corte de Madrid sobre las crecientes disensiones entre catalanes y franceses le hacían expresar ante la Junta Grande que el momento ofrecía «la mejor sazón que puede haber para ejecutar la jornada de Aragón como está resuelto». ${ }^{27}$ Creemos que, en aquellos momentos, el conde duque seguía la estrategia de jugar y activar todas las cartas posibles: la militar, la de la movilización castellana con la jornada real, la conspirativa contra Richelieu e incluso la negociadora con los catalanes, siempre, pero, desde una posición de fuerza; ello con la esperanza de que, con el tiempo, los frutos individuales o sumados de estas vías diesen el resultado apetecido de recobrar Catalunya. Con todo, su primera opción seguía siendo la de un brillante triunfo militar que reflotase la reputación del rey y la suya propia.

En esas mismas fechas en que Olivares se manifestaba con exagerado optimismo ante la Junta Grande, su ministerio había reactivado los intentos negociadores con los catalanes, ello a través de la duquesa de Cardona y del hijo de esta, don Pedro Antonio de Aragón. ${ }^{28}$ Por lo que parece, los tratos tuvieron cierta profundidad, pues la duquesa llegó a negociar con los diputados de la Generalitat; ${ }^{29}$ asimismo, el Consejo de Aragón y la Junta de Ejecución valoraron las posibilidades políticas de un acuerdo pactado. ${ }^{30}$ De nuevo, el marqués de Villafranca se mostró crítico con cualquier vía que abriese las puertas a un pacto con los rebeldes catalanes, pero Felipe IV parecía entonces abierto a un perdón real y cuando el 26 de enero de 1642 esta opción fue discutida en la Junta Grande, el rey apostilló que «yo soy padre en cualquier tiempo que venga el hijo». ${ }^{31}$ Dos días antes, el 24 de enero, se había difundido impreso un edicto o «carta pública» en que el monarca prometía el respeto a las leyes y constituciones del Principado y un perdón general a sus vasallos catalanes, afirmando que «cualesquier actos y procedimientos excessos o culpas en los movimientos y perturbaciones que han sucedido en la

27. AGS, Guerra Antigua, 1378, Junta Grande de 27 de diciembre de 1641, también ElLiOTT, J.H.: «El programa de Olivares y los movimientos de 1640» a Historia de España Menéndez Pidal, vol XXV (1982), p. 501.

28. Según informaba desde Madrid el jesuita Sebastián González a su homónimo sevillano Rafael Pereyra el 31 de diciembre de 1641, la duquesa de Cardona «está ahora en Vilareal cerca de Segorbe y de Valencia; ahora mandan parta a Huesca con poderes muy amplios para componer las diferencias de Cataluña, que hay buenas esperanzas», Cartas de algunos Padres de la Compañía de Jesús entre 1634 y 1648 en MHE vol. XVI, Madrid, 1862, p. 205.

29. El 11 de febrero de 1642 el preceptor del príncipe, Juan Idiáquez, escribía que «los negocios de composición con el Principado tienen ya más los medios que los principios, uno de los hijos de la duquesa de Cardona se avocó con algunos de sus diputados», Cartas de algunos Padres...en MHE, vol. XVI (1862), p. 262.

30. Aún la Junta de Ejecución de 19 de febrero de 1642, haciéndose eco de una consulta del Consejo de Aragón, trató «de los medios que han propuesto los catalanes para la negociación de Cataluña», AGS, Guerra Antigua, 1422, Junta de Ejecución de 19 de febrero de 1642.

31. Cfr., Elliott, John H.: El conde duque...(1990), p. 605. 
Provincia, de cualquier calidad que sean los tenemos olvidados y borrados de nuestra memoria; y aquellos y cada uno dellos reputamos por no hechos o sucedidos, de modo que ni ahora ni en tiempo alguno se puedan hazer de aquellos, o de alguno de ellos cargo alguno». ${ }^{32}$

Sin embargo esta no era la opción prioritaria de Olivares. Al mismo tiempo que daba cuerda a las negociaciones de la duquesa de Cardona con los catalanes, el conde duque avanzaba en sus planes militares, preparando -tal como detallaremos en el epígrafe siguiente- una arriesgada expedición terrestre para socorrer las plazas del Rosselló, y, sobre todo, buscaba cerrar los asientos necesarios para iniciar la jornada real de Catalunya, confiando que las remesas de la plata americana que debían llegar en marzo serían muy cuantiosas por los atrasos de la flota del año anterior.

La postración económica de Castilla, los síntomas de descontento social y la escasez de plata no eran el mejor escenario para dar confianza a los hombres de negocios que surtían de crédito a la Corona. Pero los banqueros conversos portugueses que, desde el alzamiento de diciembre de 1640, habían ligado su suerte a Olivares, acudieron en su ayuda. ${ }^{33}$ A comienzos de febrero de 1642 se cerraron algunos asientos, ello dio nuevos bríos a los proyectos militares y enterró rápidamente las opciones negociadoras. ${ }^{34}$

Desarrollando las directrices estratégicas elaboradas por el mismo Olivares en el otoño del año anterior, se dieron los primeros pasos para concentrar en la frontera de Aragón una gran fuerza militar. Además de la infantería y caballería que ya estaba disponible en Fraga y en la línea del Cinca, allí debían converger buena parte de las tropas del ejército de Tarragona y, también, la hueste reclutada en Castilla que sería encabezada por el propio monarca. A comienzos de febrero, y con gran prisa, se pidió un voto escrito a distintos mandos militares y personalidades políticas sobre la conveniencia, o no, de juntar el ejército de Tarragona con el de Aragón. El barón de Molinguen, el barón de Seebach, Simon Mascareñas, el obispo de Urgell, Manuel de Aguiar, Luis Jerónimo de Contreras entre otros, fueron consultados al respecto. La mayor parte de los pareceres eran favorables a la reunión de los dos ejércitos y los miembros de la Junta Grande del 16 de febrero ratificaron esa opinión. En el margen izquierdo de la consulta Felipe IV ordenó lo siguiente: «Como parece y ordenando al marqués de Tavara que se valga de quantos medios pudiere para que tenga aquel exército el carruaje que hubiere menester para marchar con toda celeridad». ${ }^{35}$

32. Este largo edicto fue reproducido por FELIU DE LA PEÑA, Narcís, Anales de Cataluña, Barcelona, 1709 , vol. III, p. 299-304, la cita a p. 301.

33. Ver Boyajian, James C.: Portuguese Bankers at the Madrid Court 1626-1650, New Brunswick, 1982, p. 138 s.; también Elliot, John H.: El conde duque... (1990), p. 606 s.

34. El 18 de marzo el jesuita Sebastián González escribía desde Madrid que «el marqués de Leganés parte muy en breve a tomar el cuidado de las armas de Cataluña, que parece según esto se han desvanecido las esperanzas de composición», Cartas de algunos padres..., en MHE, vol. XVI (1862), p. 293.

35. AGS, Guerra Antigua, 1422, Junta Grande de 16 de febrero de 1642. 
Estas órdenes se daban a la vez que se ultimaban los preparativos para abordar el otro objetivo militar fundamental en el frente catalán: socorrer las plazas del Rosselló asediadas por el ejército francocatalán.

\section{EL SOCORRO DEL ROSSELLÓ. LA INFAUSTA CABALGADA DEL MARQUÉS DE POVAR}

Tal como hemos visto anteriormente, una vez Tarragona fue socorrida por la armada del marqués de Villafranca y del duque de Maqueda, el mantenimiento de las fortalezas que los españoles ocupaban en el Rosselló se convirtió en una prioridad fundamental de la estrategia militar del gobierno de Madrid.

Cotlliure y, sobre todo, Salses y Perpinyà eran plazas fortificadas que si caían en manos francesas se sabía que costarían mucho de recuperar. También, el éxito o el fracaso de la anunciada jornada de Felipe IV en el frente catalán podía depender de que los franceses hubieran, o no, liberado las fuerzas que tenían entretenidas en el cerco de las plazas del Rosselló; además, el mantenimiento de las posiciones españolas en la Catalunya del Nord hacía posible que, si la ofensiva desde Aragón tuviese éxito, el ejército francés se encontrase atrapado en una pinza militar.

Sin embargo, el auxilio de tropas y vituallas a esas plazas del Rosselló era complicado y peligroso. La ruta marítima para enviar hombres, dinero y pertrechos había de remontar desde Tarragona, Els Alfacs o Vinaroz todo el litoral catalán hasta Cotlliure, ello con el único apoyo del puerto de Roses, aún en manos españolas. Esta vía era también especialmente dificultosa en la temporada de otoño e invierno por los fuertes temporales del norte y de levante que azotaban frecuentemente el golfo de León. Además, una vez las tropas y bastimentos llegaban al puerto de Cotlliure, aún habían de ser transportados a Perpinyà -la plaza principal con mayor guarnición y población civil-, quedando así expuestas a los ataques de las tropas francocatalanas.

Las expediciones de socorro alternaban los éxitos con los fracasos. Así, a finales de diciembre de 1641, el marqués de Torrecuso con 500 caballos, 2.000 infantes y un importante cargamento de víveres pasó de Els Alfacs a Cotlliure y pudo socorrer Perpinyà un mes más tarde. ${ }^{36} \mathrm{El}$ militar italiano embistió y tomó la vecina localidad de Argelers y, desde allí, a finales de enero de 1642 consiguió llegar a Perpinyà, ello a

36. Sobre la expedición del marqués de Torrecuso de enero de 1641, ver el diario de Ramon Rubí, editado por Simon, Antoni: Cròniques de la Guerra dels Segadors, Barcelona, 2003, p. 306 s; el diario de PARETS, Miquel: De molts sucsesos..., Biblioteca Universitària de Barcelona (BUB), ms. 224, fol. 85 ss, que sigue (copia) en buena parte el folleto Relació del sucsés de l'enemich intentant passar de Argelés a Perpinyà per socorrer dita vila, Barcelona, Jaume Mathevat, 1642, Biblioteca de Catalunya (BC), F. Bonsoms, 2.517. Un folleto proespañol sobre el episodio es la Relación verdadera de la grande batalla que huvo enttre franceses y españoles, sobre el socorro de Perpiñá a los 29 de enero de 1642, Pamplona, 1642, BC., F. Bonsoms x, y Biblioteca Nacional de Madrid, V.E. 53/31. También la documentación publicada por PUJOL y CAMPS, C.: MHE, vol. XXV (1893), p. 592-626, y la información que proporciona PeLlicer. José: Avisos, vol. I (2002), p. 342. 
pesar de la oposición de las tropas francocatalanas dirigidas por el marqués de Brezé, recién nombrado primer virrey francés de Catalunya.

Tan sólo unos meses más tarde, la moneda cayó de cruz para los españoles. Una expedición de seis galeras genovesas bajo el mando de Gianettino Doria que transportaban provisiones de Roses a Cotlliure, se vió dispersada por un fuerte temporal de levante a la altura del Cap de Creus. La galera capitana, con el almirante genovés a bordo, embarranco maltrecha y sin remos cerca de Blanes, donde el 7 de febrero fue asaltada y saqueada por la gente del lugar. Gianettino Doria, hijo de Carlos Doria, duque de Tursis, fue hecho prisionero y trasladado a Barcelona (11 de febrero), para posteriormente ser enviado a París. ${ }^{37}$

Una suerte bastante parecida, aunque no fue capturado, corrió el capitán Bernardino Ybarguén. Éste había recibido el 18 de enero de 1642 órdenes directas de Felipe IV de ir al Rosselló con 100.000 escudos que debían satisfacer la paga de las tropas españolas allí alojadas. Las dos galeras con las que Ybarguén se dirigió hacia Cotlliure -la San Diego y la Guzmana-toparon a la altura del Cap de Creus con las galeras de Francia que las pusieron en huida. Con el rumbo hacia el sur, a la altura de Menorca, una gran tempestad se cebó en la San Diego y en la Guzmana, obligando al comandante de los navíos a echar por la borda toda la carga que llevaban, incluidas las piezas de artillería; la situación fue tan desesperada que dicho comandante fue el primero en arrojar sus pertenencias para dar ejemplo a la tripulación. Ybarguén, sin embargo, se aferró en conservar el tesoro del rey. Después de superar la tempestad, aunque medio desarboladas, la San Diego y la Guzmana se dirigieron al puerto de Vinaroz, allí el gobernador de la plaza rechazó la responsabilidad de hacerse cargo del dinero, argumentando que una entrada desde Catalunya del ejército francocatalán podía poner en peligro el tesoro del rey. Ybarguén no tuvo más remedio que volver a Cartagena, desde donde había salido, y informar desde allí a Felipe IV del fracaso de su misión. ${ }^{38}$

Pero, para salvar las fortalezas del Rosselló, la corte de Madrid estaba dispuesta a correr grandes riesgos. En enero de 1642 se concretó un plan para socorrer dichas plazas por vía terrestre: un contingente de entre 3.500 y 4.000 hombres de caballería atravesaría Catalunya desde Tarragona a Perpinyà, siguiendo la ruta del Penedès, el Baix Llobregat, el Vallès, la Selva i l'Empordà. Se trataba, sin lugar a dudas, de una traza muy aventurada. La expedición habría de transitar durante un mínimo de siete jornadas por territorio enemigo, quedando expuesta a las emboscadas y acciones de castigo del ejército francocatalán; los vados de los ríos y, sobre todo, los pasos montañosos podían convertirse en ratoneras militares para la caballería española, la cual, además, pasaría muy cerca de Barcelona y otras ciudades que la Mothe y los mandos francocatalanes podían utilizar como bases para sus operaciones de ataque.

37. Sobre la captura de Gianettino Doria ver: PARETs, Miquel: De molts sucsesos ..., BUB, ms. 224, fol. 86 ss.; también el diario anónimo barcelonés editado por SIMON, Antoni: Cròniques ...(2003), p. 324; i el Dietari de l'Antich Consell Barceloní (DACB), vol. XIII (1911), p. 80-81.

38. AGS, Estado, 2992, Bernadino Ybarguén al rey, Cartagena 24 de abril de 1642. 
A finales de enero de 1642 el plan fue consultado a algunos militares y también a destacados exiliados felipistas. Uno de ellos, Josep Balet, antiguo asesor de la capitanía de Catalunya, se ofreció para guiar la caballería, asegurando que por las amistades que él y sus familia tenían en diversas poblaciones de la ruta proyectada (Esparreguera, Olesa, Terrassa, Girona, etc.) se podía esperar un «buen pasaje». ${ }^{39}$ Muy distinto era, sin embargo, el parecer de los hombres de armas. El experimentado Francisco Toralto, antiguo gobernador militar del Rosselló, no dudaba de la importancia de conservar aquellas plazas, pero consideraba que aquella cabalgada militar tenía casi todas las posibilidades de acabar en un fracaso: «mi parecer es que no se podrá conseguir el passar caballería a Ruissillón y que s'aventurará perderl.la por las grandes dificultades assí de l'aspereça del camino como, según tengo relación, por ser forçoso el topar con lugares grandes y cerrados y ser el viaje tan largo»; Toralto, que sería uno de los mandos militares designados para dirigir la expedición, acababa su misiva al rey dando, pero, una muestra de profesionalidad y disciplina: «con todo esso yo estoy pronto para seguir cualquiera cosa que V. Majestad fuere servido ordenarme». ${ }^{40}$

Estos juicios adversos no alteraron los planes del ministerio de Olivares. La Junta de Ejecución reunida el 4 de febrero ya hizo un cálculo económico del coste de la expedición. El gasto de las pagas de los oficiales y soldados se estimaba en 26.403 reales, a los cuales había que añadir el dinero necesario para el forraje, la pólvora y las municiones; para todo ello, en total, los miembros de la junta acordaron que se hiciese una reserva de 30.000 reales. ${ }^{41} \mathrm{Al}$ día siguiente, el 5 de febrero, la Junta Grande casi al completo, ${ }^{42}$ trató también el tema y ya preparó las órdenes y los despachos para poner en marcha la expedición de socorro del Rosselló. Llama la atención como las serias advertencias de Francisco Toralto fueron obviadas y disimuladas. En el acta de la junta se dice que se leyeron las cartas y los despachos de consulta requeridos sobre el plan «y también las que últimamente se recivieron de la duquesa de Cardona y don Francisco Toralto. Pareció a la junta que esta materia se a discurrido con fundamentos grandes, pues no sólo se an examinado las personas pláticas e inteligentes en el país, sino en lo militar y que tienen experiencia de haver pasado la tierra con tropas», añadiéndose a continuación que «no se [h] alla que acrecentar a lo resuelto», a todo lo cual Felipe IV dio su conformidad con un corto «está bien».43

Para dirigir esa arriesgada empresa militar se propuso en primera instancia a Carlo Andrea Caracciolo, marqués de Torrecuso, y a don Pedro Antonio de Aragón, marqués de Povar, hijo del difunto duque de Cardona y que hacía poco tiempo había

39. AGS, Guerra Antigua, 1419, Josep Balet al rey.

40. AGS, Guerra Antigua, 1419, Francisco de Toralto al rey. Fechada el 30 de enero de 1642 en el Camp d'Escarp (Segrià). Toralto respondía a una misiva fechada el día 26 de aquel mismo mes.

41. AGS, Guerra Antigua, 1422, Junta de Ejecución de 4 de febrero de 1642.

42. Con el cardenal Spínola, el conde duque de Olivares, el marqués de Leganés, el marqués de Santacruz, el duque de Villahermosa, el marqués de Castrofuerte, el obispo de Málaga, José González, Jerónimo Villanueva, Nicolás Cid y Pedro de Arce.

43. AGS, Guerra Antigua, 1419, Junta Grande de 5 de febrero de 1642. 
sido uno de los rehenes intercambiados por los embajadores catalanes retenidos en la corte de Madrid..$^{44}$ La presencia del marqués de Povar en la expedición tenía un carácter más político que militar, abrigándose la esperanza de que, con él, la caballería española sería mejor recibida en los pueblos y villas del Principado por donde transitase. ${ }^{45}$

La decisión de que fuese el militar italiano y no el noble catalán quien estuviese al mando supremo de la expedición, motivó la airada protesta tanto de don Pedro Antonio de Aragón como de su madre, Catalina Fernández de Córdoba, duquesa de Cardona. En una carta dirigida a Felipe IV y a Olivares, el marqués de Povar recordaba su rango y jerarquía aristocráticos -le acababa de ser concedida la grandeza- y se quejaba de que «por el puesto que su Majestad (Dios le guarde) se [h]a servido de darme es incompatible esté a la orden de nadie, y el defeto que puede tener sólo es ocupalle Yo. Y assí puniéndome a los pies de su Majestad y de V. Excelencia, le suplico me de licencia para que en pasar si es posible esta caballería sirba en la ocasión con una pica». ${ }^{46}$ Este engorroso asunto fue tratado inmediatamente por la Junta Grande, cuyos miembros se ratificaron el 16 de febrero en la decisión anterior, añadiendo el propio Felipe IV en el margen de la consulta este contundente texto: "Como parece, diziendo que yo en el caso de diferir en el parecer, elijo, apruebo y resuelvo el que tuviese el marqués de Torrecuso, con que no queda rastro de duda». ${ }^{47}$

Sin embargo, don Pedro Antonio de Aragón no estaba dispuesto a ceder y al recibir la carta real envió al conde duque de Olivares la renuncia a formar parte de la expedición, diciendo que «no estando en disposición el pasage por el qual sólo yo benía, se las he dejado y tomado una pica en su coronelía de V. E.». ${ }^{48}$ Por lo que parece la actitud del marqués de Povar tenía el soporte del marqués de la Hinojosa y de otros nobles del ejército, como el barón de Seebach y don Alvaro de Quiñones. ${ }^{49}$ Finalmente, la corte de Madrid acuciada por la necesidad de no retardar más la expedición retiró de esta al marqués de Torrecuso y dio el mando a don Pedro Antonio de Aragón, el cual debía ser asesorado por Francisco Toralto.

44. El intercambio de rehenes se había producido el 15 de noviembre de 1641 el Els Monjos (Alt Penedès), ver Dietaris de la Generalitat (DG), vol. V, Barcelona, 1999, p. 1222; y el diario anónimo barcelonés editado en Simon, Antoni: Cròniques de la Guerra...(2003), p. 323.

45. Como decía una Relación de la derrota y presa del general don Pedro de Aragón y de todo su exército, Barcelona, Gabriel Nogués, 1642, BC, F. Bonsoms, 2416, la patente a don Pedro Antonio de Aragón era por ser muy conocido en el Principado, entendiéndose que «este conocimiento obligaría a los catalanes a recibillo por amigo», fol $2 \mathrm{v}$.

46. AGS, Guerra Antigua, 1419, don Pedro Antonio de Aragón al rey, fechada en Bingana (Aragón) y recibida el 16 de enero de 1642 .

47. AGS, Guerra Antigua, 1419, Junta Grande de 16 de febrero de 1642. Al día siguiente una carta real comunicó esta decisión a don Pedro Antonio de Aragón.

48. Carta de Don Pedro Antonio de Aragón a Olivares, fechada en Reus el 24 de febrero de 1642, reproducida por PUJOL y CAMPS C.: MHE, vol. XXV (1893), p. 638-640.

49. Así se deduce de una carta enviada por Olivares al marqués de la Hinojosa, fechada el 7 de marzo de 1642 y editada por PUJOL y CAMPS, C.: MHE, vol. XXV (1893), p. 638-640. 
A mediados de marzo de 1642, con la caballería ya concentrada en Tarragona, los españoles iniciaron una serie de maniobras de diversión para intentar facilitar la travesía de la expedición dirigida por el marqués de Povar. Diversos ataques y movimientos de tropas en las zonas de Tremp, Tortosa y el coll de la Cabra intentaron distraer la atención del ejército francocatalán. Sin embargo, el plan de socorro del Rosselló no solamente era conocido por el mariscal La Mothe y los mandos francocatalanes, sino que era un proyecto de dominio público; como reconocía en su diario el exiliado felipista Ramon Rubí i Marimon, «estaba toda la provincia en arma porqué mucho antes se publicó esta jornada»..$^{50}$

El día 24 de marzo la caballería española emprendió desde el Camp de Tarragona su camino hacia el Rosselló. ${ }^{51}$ El mariscal La Mothe tuvo conocimiento inmediato de su movimiento y mandó rápidamente el alzamiento general de los somatenes del país, preparando una barrera defensiva en el paso de Sant Celoni, donde se estrecha el corredor del Vallès a los pies del Montseny. Allí, bajo las ordenes de Josep Margarit, se concentraron más de 4.000 infantes y 400 caballos. Al mismo tiempo, con la caballería francocatalana y las levas reclutadas por las ciudades -Barcelona sola movilizó 1.000 mosqueteros y otras tropas de caballería e infantería-, el mariscal francés se dedicó a castigar la retaguardia de la expedición española, la cual, el 25 de marzo, al vadear el Llobregat por Olesa, perdió más de doscientos hombres. Tres días después, el 28 de marzo, cuando la hueste dirigida por el marqués de Povar ya se adentraba por el corredor del Vallès, La Mothe volvió a castigar su retaguardia cerca de la localidad de Montmeló; allí, entre muertos, heridos y prisioneros, los españoles perdieron cerca de mil hombres. Con la fuerte barrera de Sant Celoni enfrente y con la caballería y mosqueteria de La Mothe a sus espaldas, la cansada y ostigada expedición española intentó volver sobre sus pasos para retornar a sus bases del Camp de Tarragona. Sin embargo, la mañana del 31 de marzo, la expedición del marqués de Povar fue alcanzada y rodeada por las tropas de La Mothe, Margarit, d'Ardena, Sorribes, Terrail y Merenville cerca de Vilafranca del Penedès, en la ermita de Sant Jordi, rindiéndose sin apenas resistencia.

A las cuatro de la tarde de ese mismo día 31 de marzo, tres correos llegaron a la capital catalana comunicando la noticia de la derrota de la caballería española. ${ }^{52}$ Aquel mismo día, y durante los siguientes, los barceloneses celebraron con Tedeums, disparos de artillería y solemnes procesiones un triunfo considerado memorable; un anónimo dietarista barcelonés resalta «lo júbilo y alegria que en esta ciutat y hagué lo

50. Editado por Simon, Antoni: Cròniques de la Guerra ...(2003), p. 308.

51. Sobre este episodio militar ver SANABRE, Josep: La acción de Francia...(1956), p. 200-202; así como diversas relaciones y diarios coetáneos: Relación de la derrota...(1642), BC, F. Bonsoms, 2416; PARETS, Miquel: De molts sucsesos..., BUB, ms. 224, fol. 87 ss, que sigue la relación antes citada; también los diarios de Ramon Rubí y el anónimo barcelonés editados por SimON, Antoni: Cròniques de la Guerra... (2003), p. 308 ss. Y 326 ss.

52. $D A C B$, vol. XIII (1911), p. 104. 
darrer dia del mes de mars, quant arribà la nova, és cosa increíble vèurer la gent que va acudir a la Seu a fer gràtias a nostra gloriosa verge y patrona santa Eulàlia». ${ }^{53}$

Dos días más tarde, el 2 de abril, entraron en Barcelona el marqués de Povar, Francisco Toralto y los demás capitanes, maestres de campo, comisarios, sargentos y alféreces prisioneros del ejército español; según el dietario de la Generalitat, la entrada de los prisioneros causó una gran expectación en la capital catalana: «la gent que.ls hisqué a vèurer no tenia número, perqué no restaren a penes hòmens ni dones de la present ciutat que no.ls anassen a vèurer». ${ }^{54}$

La derrota y captura de la caballería dirigida por el marqués de Povar para socorrer Perpinyà fue bastante más que una «escaramuza» previa a la campaña de Aragón que encabezaría Felipe IV. ${ }^{55}$ Sus trascendencias fueron muy relevantes: el fracaso de la expedición sumado a la caída del puerto de Cotlliure (13 de abril), dejó completamente aisladas Perpinyà y Salses, siendo su conquista a manos del ejército francocatalán sólo cuestión de tiempo. Asimismo, el espectáculo de ver desfilar prisioneros por las calles de Barcelona a cientos de afamados hombres de armas del ejército español, reforzó, sin lugar a dudas, la reputación de La Mothe entre los catalanes; también, el ejército francocatalán se vio fortalecido por el bagage y los caballos capturados a los españoles. Finalmente, esta derrota tuvo también importantes consecuencias políticas, ya que contribuyó a acelerar el inicio de la jornada real sobre Cataluña, pues Felipe IV se mostraba cada vez más ansioso por reflotar su reputación.

El duro golpe que en la corte de Madrid supuso el conocimiento del descalabro del marqués de Povar en tierras catalanas, lo refleja José Pellicer en sus Avisos: «La desdichada nueva de la pérdida del señor don Pedro de Aragón i su exército, que sucedió a 27 del passado, ha lastimado grandemente los corazones de todos, por ser, en esta saçon i a tal tiempo, la mayor desgracia que ha sucedido a esta Monarchía i de que se han de seguir peligrosísimas consequencias, no solo por haverse enflaquecido nuestras armas, como por haverse engrossado las de los enemigos». ${ }^{56}$ De una manera parecida, el exiliado Ramon Rubí expresaba con desazón que «Fue gran pérdida por todas consideraciones y también porque el enemigo nos hace la guerra con nuestra caballería». ${ }^{57}$

\section{DOS REYES EN CAMPAÑA}

La decisión de Luís XIII de ir personalmente al frente catalán, saliendo de Fointenebleau el 27 de enero de 1642, puso a Olivares en una situación muy delicada, pues ahora, fuesen cuales fuesen las circunstancias militares y financieras, difícilmente Felipe IV podría eludir aquel envite y renunciar a la jornada real para la conquista de Catalunya tantas veces anunciada. Ahora, más que nunca, la reputación del monarca

53. Editado por SIMON, Antoni: Cròniques de la Guerra ...(2003), p. 327.

54. $D G$, vol. V (1999), p. 1246.

55. Este es el juicio del episodio expresado por ElLiotT, John H.: El conde duque...(1990), p. 608.

56. Pellicer, José: Avisos, vol. I (2002), p 358 s.

57. Editado por Simon, Antoni Cròniques de la Guerra...(2003), p. 309. 
estaba en juego, ya que como escribía Matías de Novoa, la novedad de la venida a la frontera del Rosselló del monarca francés «tenía el mundo atento y a toda España en suspensión». ${ }^{58}$

A finales de febrero de 1642, Felipe IV había enviado un billete a Olivares ordenando que «las prevenciones de la jornada se ajustasen como si huviese de ser esta semana», $y$, para intentar satisfacer la voluntad real, la Junta de Ejecución se reunió el día 2 de marzo con el objeto de discurrir sobre «todo lo que combenía prevenir para que sin dilación tuviese efecto lo que V. Majestad ordena». ${ }^{59}$ Los miembros de la junta, con Olivares al frente, concretaron en un total de veintisiete puntos estas prevenciones para la jornada real, las cuales pasaban por ajustar como debía quedar organizado el gobierno en Madrid en ausencia del monarca, en la movilización de los hombres y bastimentos que acompañarían al rey hacia tierras de Aragón, en los nombramientos de los militares responsables de las capitanías de las distintas provincias de España, así como de los principales encargados de la intendencia de la jornada real. Un impaciente Felipe IV dio el visto bueno a todas estas disposiciones, anotando en el margen de la consulta «como parece, caminándose en todo muy aprisa, pues ya es tarde para todo».

Estas ansias reales contrastaban, sin embargo, con un empeoramiento del escenario militar y financiero en que se tenía que desarrollar la campaña real. En las semanas que siguieron a la citada reunión de la Junta de Ejecución, dos serios contratiempos complicaron aún más los triunfales planes diseñados por el conde duque de Olivares a finales de agosto del año anterior. Tal como hemos detallado en el epígrafe anterior, a finales de marzo el fracaso de la caballería del marqués de Povar en su intento de socorro del Rosselló, unido a la posterior caída de Cotlliure, dejó aislada Perpinyà. Prácticamente coincidiendo con este desastre militar, la llegada de los galeones de la flota de Tierra Firme a Cádiz dio lugar a otra gran decepción: la plata de las Indias sólo llegó en la exigua cantidad de 300.000 ducados, el fraude en el registro era de tal magnitud que el propio general de la armada, Francisco Diaz Pimienta, lo comunicó al rey. ${ }^{60}$

Con una rapidez parecida a la caída de un castillo de naipes, todas las bazas proyectadas tan sólo medio año antes por el conde duque para preparar la expedición real al frente catalán, se iban desmoronando una tras otra; sin embargo, aún quedaba alguna. Si Richelieu había jugado a debilitar a la monarquía católica dando apoyo a las rebeliones de la periferia hispana, el conde duque buscaba aliados en la oposición aristocrática francesa que conspiraba para derribar al privado de Luís XIII. A mediados de marzo de 1642, a través de una legación del marqués de Fontrailles, un sector de la oposición de la aristocracia gala contraria a Richelieu concertó un tratado secreto con Olivares; según dicho acuerdo un ejercito invasor español recibiría ayuda para

58. NovoA, Matías de: Historia de Felipe $I V$, en este artículo cito a partir e la edición realizada por el marqués de la Fuensanta y José Rayón, Madrid, tomo IV, 1886, la cita en p. 20

59. AGS, Guerra Antigua, 1423, Junta de Ejecución de 2 de marzo de 1642.

60. Cfr. Elliott, John H.: El conde duque...(1990), p. 609; y Álvarez NogAL, Carlos: El crédito de la monarquía...(1997), p. 272. 
entrar en Francia y derribar el gobierno de Richelieu, concertándose posteriormente un tratado de paz entre las dos monarquías. Esta conspiración, que contaba con la complicidad de Gastón de Orleáns y la reina Ana, fue, sin embargo, puesta al descubierto y desarbolada por el cardenal francés en los meses siguientes, acabando Cinq-Mars y Thou ejecutados en el cadalso. ${ }^{61}$

A mediados de abril, la noticia de la derrota y captura de la caballería del marqués de Povar sumada a los avisos de que el rey de Francia se aproximaba al sitio de Perpinyà, aumentaron la presión popular para la salida del rey, el cual era acusado de cobardía. En palabras de Martin Hume «sátiras y epigramas cayeron en Madrid como las hojas en otoño»; ${ }^{62}$ acelerando la resolución de Felipe IV de partir hacia el frente de guerra. ${ }^{63}$ Esta era, sin embargo, una decisión forzada por criterios de prestigio político, pues no existían las adecuadas condiciones militares y financieras para realizar la jornada real. Según informa en su correspondencia el jesuita Francisco de Espinosa, el experimentado marqués de Torrecuso era del «parecer que no se haga», aventurando que si la expedición acababa en un fracaso, sería «grande desaire» para el rey. ${ }^{64}$ En aquellos momentos todo parece indicar que Olivares pensaba de una manera parecida y que era perfectamente consciente de los grandes riesgos que implicaba la salida de Felipe IV hacia el frente catalán, sin embargo, ahora, difícilmente podía poner freno a aquella empresa que el mismo había impulsado tras la euforia del socorro de Tarragona. Era difícil contener un estado de opinión que, según Matías de Novoa veía «un rey de Francia metido entre las balas y la pólvora, y que la España que poco há era de un rey, tenía tres». ${ }^{65}$

Finalmente, el día 26 de abril, Felipe IV salió de Madrid después de visitar la virgen de Atocha, dando sin embargo durante el mes siguiente diversos tumbos por Barajas, Alcalá de Henares, Loeches y Aranjuez; de hecho, sólo a partir del 23 de mayo salió el monarca hacia tierras aragonesas pasando por Cuenca y Molina de Aragón, para llegar a Zaragoza el día 27 de julio. Este lento y largo viaje, que consumió buena parte de la estación propicia para las operaciones bélicas, cabe interpretarlo, tal como hace J.H. Elliott, como una consecuencia de las insuficiencias administrativas y, sobre todo, financieras con que se abordó la jornada real. ${ }^{66}$ Sin apenas plata americana, las fuerzas de una desgastada Castilla eran insuficientes para ese nuevo reto militar. Un memorial satírico que se divulgó en Madrid durante el mes de mayo, retrataba con

61. Sobre esta conspiración, ver básicamente ERLANGUER, Phillipe: Cinc Mars ou la passion et la fatalité, París, 1962 ; y ElLiott, John H.: Richelieu y Olivares, Barcelona, 1984, p. 193 ss.

62. Hume, Martin: La corte de Felipe IV, Barcelona, 1949, p. 212.

63. Según NovoA, Matías de: «Con que, y con el aviso de la entrada del Cristianísimo, por las fronteras de Perpiñan, en el Rossellón y en España, resolvió la suya [el rey]», Historia de Felipe IV...(1886), p. 20.

64. Cartas de algunos Padres..., en MHE vol. XVI (1862), fechada en Madrid el 8 de abril de 1642, p. 322. 65. NovoA, Matías de: Historia de Felipe IV ...(1886), p. 21.

66. Cfr., Elliott, John H.: El conde duque...(1990), p. 609. 
crudeza la postración castellana: «Los vasallos ya están contentos, pues ni tienen más que dar, ni Vuestra Majestad más que pedir». ${ }^{67}$

El ministerio de Olivares se vio incapaz de organizar y avituallar convenientemente el ejército que tenía que acompañar al rey. El testimonio personal de Matías de Novoa es demoledor al afirmar que «tanto como allí se juntaba no parecía nada, porque la gente baja huía del hambre, y solos los honrados persistían, porque no había gobierno» ${ }^{68}$ El mismo Novoa observaba como el tiempo iba pasando sin síntomas de emprenderse ninguna acción militar, mostrándose a comienzos de septiembre no tan sólo crítico sino indignado: «y en lo tocante a las necesidades y remedio de España y reducción de Cataluña no se hacía nada: los aprestos y ruidos de las armas eran muchos y vanos, los consejos inútiles, el ejército no tenía forma, y Zaragoza era la plaza de armas de los vicios y las delicias, donde se divertían los hombres que habían de ser prez de los hechos y de las hazañas; la honra de la nación oscurecía». ${ }^{69}$

Evidentemente, la suerte en el campo de batalla no estaba preescrita, pero aquellas no era las mejores circunstancias para una jornada real victoriosa. De lo que Olivares había diseñado sobre el papel un año antes, ya no quedaba prácticamente nada.

\section{TENIENTE GENERAL DE LA DERROTA. LOS REVESES DE PERPINYÀ Y LLEIDA}

Cuando a comienzos del mes de abril de 1642 la resolución de Felipe IV de partir hacia el frente de Aragón ya no tenía marcha atrás, el rey decidió nombrar a Olivares teniente general de todos los ejércitos de España. El despacho oficial de este título que fue comunicado al virrey de Aragón, marqués de Tavara, el día 21 de mayo, disponía que el conde duque tendría a sus órdenes toda la milicia de infantería, caballería y artillería de los «exércitos de España y en las islas adyacentes della», así como las armadas navales de galeras. El rey dejaba en los hombros de su privado «toda la potestad y jurisdicción que nos compete», transmitiéndole explícitamente los poderes militares que, en última instancia, iban ligados a su condición de soberano: «y es nuestra voluntad, que todas las órdenes y mandatos vuestros se cumplan y obedezcan y ejecuten como si Nos mismo los diéramos». ${ }^{70}$

Quizás más que una muestra de gran confianza en las capacidades militares de Olivares, Felipe IV quería que este asumiese sus responsabilidades en una empresa que, impulsada y diseñada por el conde duque siete meses atrás, ahora, en abril de 1642, comportaba importantes riesgos, los cuales, sin embargo, el monarca difícilmente podía eludir, especialmente desde que Luis XIII de Francia había anunciado su presencia en el frente catalán.

67. Reproducido en Cartas de algunos Padres..., en MHE vol. XVI (1862), p. 378.

68. NovoA, Matías de: Historia de Felipe IV... (1886), p. 54.

69. Ibid., p. 58.

70. El documento del título militar de Olivares fue publicado por TOMÁs y VALIENTE, Francisco: Los válidos en la monarquía española del siglo XVII. Estudio institucional, Madrid, 1963, apéndice VII, p. 175-184. 
El 6 de abril, unos días más tarde de que llegase a su conocimiento el nombramiento de teniente general de los ejércitos, el conde duque dirigió a Felipe IV una carta donde reflexionaba sobre la responsabilidad que le había sido concedida; esta era una misiva que lejos de reflejar un sentimiento de alegría por el honor recibido, transmitía un estado de profunda desazón y abatimiento; incluso, al final del escrito, el conde duque pedía al monarca su relevo político: «propongo a V. Majestad que pueda servirse de mandarme jubilar en mis ministerios con gajes o sin ellos, pues este accidente tan natural ha obligado a ello, que en 20 años jubilan al más triste catedrático y yo ha 21 que sirvo, y el faltar la salud y las fuerzas no es culpa ni demérito sino un suceso, el más frecuente y natural de cuantos hay en el mundo». ${ }^{71}$

Aunque Olivares tuviera grandes dudas y temores sobre el resultado de la anunciada jornada de Cataluña, y hubiese preferido no iniciarla en aquellas circunstancias, al igual que Felipe IV tampoco tenía opciones, pues su deber era acompañar al monarca y dirigir el aparato militar y administrativo que le había sido confiado.

A partir del mes de abril de 1642 las operaciones militares en el frente catalán se desarrollaron en dos escenarios principales: el primero a lo largo de la zona fronteriza catalana-aragonesa que, de sur a norte, iba desde las tierras del Ebro hasta el condado de la Ribagorza. El segundo escenario se situaba en el Rosselló, donde los españoles aún mantenían las plazas de Salses y Perpinyà, las cuales, pero, des de la caída de Cotlliure (13 de abril) no podían ser socorridas, quedando «al cuchillo del hambre» en palabras de Matías de Novoa. ${ }^{72}$

Existía un tercer escenario militar: el marítimo, en el cual la corte de Madrid había depositado grandes esperanzas, especialmente desde que la armada del mediterráneo fuese reforzada por los navíos que el duque de Ciudad Real había llevado desde Cádiz, y desde que el príncipe Juan Carlos de Médicis, hermano del Gran Duque de Toscana, hubiese traído también al levante peninsular diversas galeras italianas, relevando a la vez al marqués de Villafranca como comandante de la escuadra hispana. Sin embargo, a pesar de la superioridad numérica de la armada española sobre la francesa, ${ }^{73}$ a lo largo de aquel año de 1642 apenas hubo acciones navales de importancia. ${ }^{74}$ Matías de Novoa describía así la táctica seguida por la armada gala: « no aferrar con ningún navío de España; no pelear, sino que al que quedase zorrero acometerle de lejos, siendo solo, echarle fuego y quemarle», y la comparaba con la que la flota de Isabel de Inglaterra

71. Carta editada por Elliott, John H. y PEÑA, Francisco de la: Memoriales y cartas del conde duque de Olivares, vol. II, Madrid, 1981, p. 217-219, la cita en p. 219.

72. NovoA, Matías de: Historia de Felipe IV...(1886), p. 22.

73. Según informa NovoA, Matías de: la armada francesa disponía de 9 bajeles y 17 galeras, mientras la española de 42 bajeles y 10 galeras españolas, las cuales fueron después engrosadas por las italianas, Historia de Felipe IV...(1886), p. 48 s.

74. Uno de los pocos episodios navales militarmente relevante fue el combate que en los días fínales de junio de 1642 hubo delante de Barcelona entre la escuadra francesa de Brezé y la española dirigida por el duque de Ciudad Real, combate que, sin embargo, no tuvo un carácter decisivo, ver SANABRE, Josep: La acción de Francia...(1956), p. 228 s. 
había empleado para desbaratar la Invencible. ${ }^{75}$ Tampoco los españoles pudieron conquistar ningún puerto en el litoral catalán, apoderándose de los círculos cortesanos un sentimiento de decepción por esta inoperancia naval que el cronista Matías de Novoa reflejaba con estas palabras: «estos fueron los sucesos de nuestra armada, en que se gastaron algunos millones, dejando con desconsuelo a los vasallos que sus efectos no fuesen relevantes, ni la esperanza como se había prometido». ${ }^{76}$

A mediados de abril de 1642, cuando el bando franco-catalán aún relamía las mieles del triunfo del Penedès sobre la caballería del marqués de Povar, el mariscal La Mothe decidió emprender la conquista de Tortosa. La capital del Baix Ebre, en poder de los españoles desde septiembre de 1640, era una plaza de gran valor estratégico. Tortosa había sido utilizada por el ejército del marqués de Los Vélez como cabeza de puente de la invasión castellana que acabó con la derrota de Montjuïc, pero para los francocatalanes su conquista no solamente significaba desbaratar esta palanca de los ataques españoles y hacer del Ebro una trinchera de defensa, aquella plaza amurallada y dominada por el castillo de La Suda podía también convertirse en una base para amenazar y «cortar» las líneas militares hispanas del reino de Valencia y del sur de Aragón.

Con 8.000 infantes y 2.000 caballos, La Mothe puso cerco a Tortosa el 26 de abril de 1642. Los defensores contaban con 1.500 soldados castellanos y 300 caballos además de una milicia ciudadana de 800 hombres. ${ }^{77}$ Además de su manifiesta superioridad numérica, La Mothe confiaba en un alzamiento de los tortosinos contrarios a la dominación española y también en que algunos puntos débiles de las murallas serían presa fácil de la artillería francesa, la cual no debía hallar oposición en las dos únicas piezas artilleras con que contaban los defensores.

Las demandas urgentes de socorro por parte de los mandos militares que dirigían la guarnición de la plaza, con el gobernador Bartolomé de Medina al frente, no pudieron ser atendidas ni por Olivares desde la corte, ni por el marqués de Leganés en Valencia, ni tampoco por los marqueses de Tavara en Zaragoza y de La Hinojosa en Tarragona.

A comienzos de mayo de 1642 la situación de Tortosa parecía desesperada y en su correspondencia con Olivares, el marqués de Leganés la daba prácticamente por perdida. ${ }^{78}$ El día 3 de mayo la artillería de La Mothe consiguió abrir una considerable brecha en la muralla pero el asalto subsiguiente fue rechazado por la tenaz resistencia de una guarnición alentada por el espíritu religioso del obispo Giovanni-Batista Veschi, quien

75. NovoA, Matías de: Historia de Felipe IV... (1886), p. 49.

76. Ibid., p. 51.

77. Sobre el asedio de Tortosa ver básicamente QUEROL, Enric y MUÑOZ, Joan Hilari: La Guerra dels Segadors a Tortosa (1640-1651), Valls, 2004, p. 85 ss; también SANABRE, Josep: La acción de Francia ... (1956), p. 208 ss.

78. En una carta fechada el 1 de mayo de 1642, Leganés, preveyendo la pérdida de Tortosa aconsejaba al conde duque asegurar Tarragona y articular una barrera fortificada en la línea de Peñíscola-BenicarlóMorella para salvaguardar el reino de Valencia, Cfr., QUEROL, Enric y MUÑOZ, Joan Hilari: La Guerra dels Segadors...(2004), p. 90 s. 
llevó personalmente la imagen de la Inmaculada Concepción al fragor de la batalla que se mantenía en las murallas. Dos días más tarde, ante el elevado coste humano del asalto, La Mothe levantó el sitio y dirigió su ejército hacia las tierras de Lleida.

Cuando la noticia de la victoriosa defensa de Tortosa llegó a Madrid, la capital de la monarquía vivió un sentimiento de euforia equiparable al del éxito del auxilio naval de Tarragona de agosto de 1641. En poco tiempo de la imprentas de Madrid y Sevilla salieron publicados tres folletos sobre aquel episodio de armas donde había quedado demostrado que «mil quinientos castellanos sobran para mil mundos». ${ }^{79}$

Inmediatamente después de su fracaso en las tierras del Ebro, La Mothe, preveyendo la ofensiva militar que conllevaría la jornada real de Cataluña, intentó mejorar sus posiciones en la zona del Segre, del Cinca y de la Ribagorza. Desde la segunda quincena de mayo hasta comienzos de julio sus tropas castigaron duramente las comarcas de La Llitera y de la Ribagorza. Las talas de los campos y las conquistas de Tamarit, Monzón, Benavarre, Estadilla, Maella entre otras poblaciones, fueron seguidas del pillaje y del incendio, cosa que provocó el éxodo de sus habitantes y una desertización de aquella zona del frente, un objetivo seguramente buscado por los mandos franceses. ${ }^{80}$ La caída de Monzón y su castillo (16 de junio) fue especialmente acusada por los españoles debido a la significación política de esta villa aragonesa; según el testimonio de Matías de Novoa, «fue esta pérdida de gran dolor para el reino y para Madrid, porqué como aquellos hombres tenían noticia del lugar donde los reyes llaman cortes, y las han tenido a todos los tres reinos, creyeron que era gran lugar y la pérdida muy grande». ${ }^{81}$

Tal como hemos dicho, el Rosselló era el otro gran escenario terrestre de las operaciones del frente catalán. Tanto para Olivares como para Richelieu, el dominio de las plazas fortificadas de esos territorios del norte de Catalunya constituía una prioridad militar. La campaña francesa iniciada por el príncipe de Condé el verano de 1641 y continuada después por el mariscal du Brezé, primer virrey francés de Catalunya, fue encaminada desde el primer momento a dejar Perpinyà aislada. La caída de Elna (junio de 1641) y después de otras plazas que se encontraban en poder de los españoles como Canet y Cotlliure, fue apretando la argolla que ceñía la capital del Rosselló. ${ }^{82}$

79. Esta cita sale del opúsculo Defensa del sitio de Tortosa publicado en Madrid por Catalina de Barrio el 1642. Los otros dos folletos son: Verdadera relación de la defensa y sitio de la ciudad de Tortosa rora por las armas francesas..., publicado en Sevilla por Juan Gómez de Blas el 1642; y Segunda relación más copiosa de la defensa y sitio de Tortosa con noticias particulares de la victoria, publicado en Madrid por Catalina de Barrio el 1642.

80. Sobre la campaña francesa en la frontera de Aragón, ver básicamente: SANZ CAMAÑES, Porfirio: Estrategias de poder y guerra de frontera. Aragón en la Guerra de secesión catalana (1640-1652), Monzón, 2001, p. 88 ss.

81. NovoA, Matías de: Historia de Felipe IV ...(1886), p. 35.

82. Sobre el sitio de Perpinyà pueden verse las narraciones de los diarios personales de Pere Pasqual y Jeroni Cros editados por Simon, Antoni y VILA, Pep: Cròniques del Rosselló. Segles XVI-XVII, Barcelona, 1998, y también una literatura coetánea impresa: Relación verdadera de todo lo que ha pasado en Perpiñán el tiempo que estuvieron cercados..., Barcelona, 1642; Relació molt fidedigna de tot lo que succehi a 
El descalabro, ya referido, de la expedición de socorro del marqués de Povar en los últimos días del mes de marzo, prácticamente coincidió con la llegada al Rosselló de un gran ejército francés encabezado por el mismo monarca Luis XIII y por el cardenal Richelieu. A mediados de abril el rey Cristianísimo se asentó cerca de Perpinyà con más de veinte mil hombres, a cuyo mando había puesto algunos de sus mejores generales y ministros: Meilleraye, Turenne, Shomberg, Noyers y Chavigny. Aunque por razones políticas (el ya comentado complot del señor Cinq-Mars) y de salud, Richelieu y Luis XIII abandonasen el sitio de Perpinyà antes de su caída, no existen dudas sobre la gran importancia política y estratégica que, por parte francesa, se otorgaba a la conquista de la plaza. La correspondencia de Richelieu ofrece multitud de testimonios de ello. Así, en una carta de comienzos de agosto de 1642 dirigida a Noyers, el cardenal declaraba que «si el Rey conquista Perpiñán, este año será muy glorioso y sus negocios quedarán en excelente estado; si por lo contrario, no lo consiguiera, sería una mengua de la reputación a los negocios de Francia»». ${ }^{83}$

Perpinyà era defendida por una guarnición española de 3.000 hombres al mando del marqués Flores de Ávila. A finales del año 1641, la situación dentro de las murallas de la ciudad ya era dramática. Además de la falta de toda clase de víveres y de la extensión de las enfermedades, la vida de los asediados era crispada por los continuos enfrentamientos entre los soldados españoles y la población civil perpinyanesa. El diario del notario Pere Pasqual refleja con crudeza la vida de la plaza en aquellos momentos; dejando este notario perpinyanés este testimonio para sus descendientes: «Mos fills ab la present memoria vos prech no habiteu en tot Rosselló, sinó que vos transferían en qualsevol part per lo que, estant y contribuint ab ells [los soldados], és estat pyor que no ab los dimonis de l'infern, que per rahó que estam acitiats nos morim de fam [...] Los meus fills o decendents, vos prech molt a las veras que, si hoiu mormon de guerra, vos absenteu de allí la hoireu anomenar, vehent que los soldats són molt pyor que no hiretgas, tractant y robant-nos pyor que si fossen postres senyors y nosaltres perros» $;{ }^{84}$ para añadir en su diario el mes de enero del año siguiente que «y ara que no y ha ni.s troba cans, gats, ni ratas, som arribats en temps que menjem solas de sebatas y pregamins remollats y totas generations d'erbas». ${ }^{85}$

La situación de los soldados era igualmente penosa y al agudizarse la falta de alimentos en la plaza se dieron casos de necrofagia y canibalismo; ${ }^{86}$ sin embargo, el mar-

l'exir de Perpinyà los marquès de Flores de Ávila..., Barcelona, 1642; también se pueden consultar las historias de la ciudad, especialmente WolfF, Ph. et alii: Histoire de Perpiñan, Tolouse, 1985, p.78-80; y la bibliografía más especializada de VASSAL REIG, Ch.: La prise de Perpignan, París, 1939, y SANABRE, Josep: La acción de Francia...(1956), p. 219 ss.

83. Avenel, Lettres du Cardinal Richelieu, Paris, vol. VII, p. 67, citada por SANABRE, Josep. La acción de Francia...(1956), p. 230.

84. Editado por Simon, Antoni y ViLA, Pep: Cròniques del Rosselló...(1998), p. 117.

85. Ibid., p. 122.

86. Diversas crónicas y testimonios recogen estos casos. Así, por ejemplo, en una carta fechada en Zaragoza el 4 de octubre de 1642, el marqués de Algara, explicaba que Diego Cavallero, militar que había defendi- 
qués Flores de Ávila alargaba la resistencia esperando refuerzos y víveres de una expedición de socorro. Después de la fracasada cabalgada del marqués de Povar, hubo otros proyectos para auxiliar Perpinyà. El día 20 de junio de 1642, la Junta de Ejecución con la intervención directa de Olivares, programó una expedición de socorro al Rosselló que tenía que dirigir el marqués de Torrecuso ${ }^{87}$ y ocho días más tarde, la misma Junta de Ejecución discutió una detallada propuesta del marqués de Tavara, virrey de Aragón, para machar hacia Perpinyà con un ejército de 7.000 infantes y 3.000 caballos. ${ }^{88}$ Sin embargo, preveyendo esta posibilidad, los mandos francocatalanes habían fortificado las vías de paso que conducían al Rosselló y el temor que se repitiese un fracaso como el sufrido por el marqués de Povar, acabó por anular todas las iniciativas. ${ }^{89}$

Con la plaza diezmada por el hambre y las enfermedades, y perdidas las esperanzas de recibir un auxilio del exterior, el 29 de agosto de 1642 los mandos españoles de Perpinyà pactaron la capitulación de la plaza. En virtud del acuerdo firmado por Flores de Ávila y los mariscales Shomberg y Meilleraye, la guarnición hispana abandonó Perpinyà el dia 9 de septiembre con todos los honores militares y llevando su propio armamento, dirigiéndose a los puertos de Roses y Tarragona. La caída de la capital de Rosselló arrastró la de Salses que capituló el día 15 de septiembre, abandonado la guarnición española la plaza el 29 del mismo mes. Desde entonces todo el Rosselló estaba en manos francesas.

La toma de Perpinyà fue celebrada en la corte de Paris con grandes pompas religiosas y profanas..$^{90}$ Un eco mayor tuvo aún aquella victoria en la capital catalana, según informa una relación coetánea, «a 10 de setiembre, a las tres de la tarde, llegó a Barcelona la feliz nueva del rendimiento de la villa y castillo de Perpiñán; fue tan grande y universal el júbilo por toda la ciudad que iban las gentes por las calles dándose parabienes unos a otros gritando ¡Viva Francia!! ¡Viva nuestro rey!». ${ }^{91}$ El zurrador Miquel Parets nos confirma la euforia desbordada que se vivía en Barcelona al anotar en su diario que la gente «no cabien en sí», dejando a la vez testimonio de algunos hechos singulares de dichas celebraciones, como la fuente de vino que hizo en su casa el deán de la catedral Pau del Rosso: «que va rajar tot lo dia i allí ne prenia qui.n volia,

do Perpinyà, le refirió que los soldados habían comido carne humana y también sus propios excrementos, mientras que «el regalo para los enfermos era sangrar los caballos para darles sangre frita», Cartas de algunos Padres..., en MHE, vol. XVI, Madrid, 1862, p. 468

87. AGS, Guerra Antigua, 1422, Junta de Ejecución de 20 de junio de 1642.

88. AGS, Guerra Antigua, 1422, Junta de Ejecución de 28 de junio de 1642.

89. Según informa NovoA, Matías de: el mariscal La Mothe estaba «atento» a los planes españoles, «ocupando los pasos de Lérida hasta Barcelona, para defender que no pasase socorro a Perpiñán, creyendo cogerle como los caballos de D. Pedro de Aragón», Historia de Felipe IV ... (1886), p. 53.

90. Cfr., SANABRE, Josep: La acción de Francia...(1956), p. 231.

91. Relación sucinta de lo que se hizo en Barcelona cuando llegó la nueva del rendimiento de Perpignán y las solemnes luminarias que se hicieron, Barcelona, 1642. 
que y acudia molta gent; y en diferens vegades, va llansar per la finestra trenta lliuras de moneda, y que la aplegàs qui pogués»». ${ }^{92}$

Cuando Olivares recibió la noticia en Zaragoza, el todopoderoso privado acusó el golpe y, según el testimonio del embajador veneciano Niccolò Sagrado, se postró ante Felipe IV bañado de lágrimas y pidiendo permiso para arrojarse por la ventana. ${ }^{93}$ Independientemente de la teatralidad del gesto, buscada o no, el conde duque sabía que la pérdida de Perpinyà representaba una importante mengua de la reputación real y que ello, inevitablemente, tenía un coste para su propia posición política. Una sensación de fracaso se extendió por doquier; según percibía Matías de Novoa, el revés de Perpinyà, «fue grande quebranto para el Rey y para todo el Reino, y aún para los extranjeros, para Alemania, para Flandes y para Italia: decían que se había perdido de las dos llaves españolas una, de los dos ejes del Pirineo el uno. El decaecimiento fue grande». ${ }^{94}$

Para los súbditos de la Corona de Castilla la mala noticia de la pérdida de Perpinyà fue acompañada de otra grave alteración de la moneda. Para atajar la espiral inflacionista que habían desatado las subidas del vellón decretadas en los dos últimos años, las cuales habían disparado el premio de la plata hasta un 200 por 100, el 15 de septiembre de 1642 se produjo una drástica deflación: por una pragmática real las piezas de cobre de ocho y doce maravedís redujeron a dos su valor, sufriendo las otras piezas de vellón unas bajas parecidas. ${ }^{95}$ Según informa José Pellicer en sus Avisos, en aquella jornada hubo una «gran confusión» resultando que al día siguiente «apenas se halla que comer». ${ }^{96}$

La pérdida de Perpinyà hizo que Felipe IV urgiera a sus generales una acción sobre Lleida y aunque con un mal orden en la milicia, y sobre todo en la intendencia, el marqués de Leganés, primo de Olivares, pudo juntar cerca de Fraga un ejército de 20.000 hombres. Enfrente, las tropas francocatalanas de La Mothe sumaban 13.000 efectivos. El día 7 de octubre se produjo un choque encarnizado en las afueras de Lleida que terminó, entrada ya la noche, con la retirada de los españoles. El repliegue de las tropas de Leganés hacia Zaragoza se convirtió en una pesadilla, pues muchos soldados murieron ahogados en los ríos o víctimas de la falta de alimentos y asistencias. Las pérdidas fueron muy considerables: unos 5.000 hombres entre los cuales se contaban

92. PARETs, Miquel : De molts sucsesos..., BUB, ms. 224, fol. 99.

93. Cfr., Elliott, John H.: El conde duque.. (1990), p. 616. A pesar de todo, Olivares elaboró inmediatamente un plan militar de 44 puntos «sobre lo que convendrá que obren los ejércitos después de la pérdida de Perpiñán», Archivo Histórico Nacional de Madrid, Estado, leg. 860.

94. NovoA, Matías de: Historia de Felipe IV... (1886), p. 59.

95. Cfr., Domínguez OrTiz, Antonio: Política y hacienda... (1960), p. 262.

96. Pellicer, José: Avisos, vol. I (2002), p. 407. Por su parte, Matías de NovoA se refiere a los duros efectos de la baja de vellón, diciendo: «A mediados de septiembre de este año, algo más, ejecutaron la determinación impía del vellón, tanto, que ya se veían las médulas de los huesos de los vasallos, porque ya no les había quedado sangre de las cuchilladas. Fue este día grande de lágrimas y sollozos para el pueblo», Historia de Felipe IV...(1886), p. 60. 
400 oficiales y unos 300 caballeros de las órdenes militares. ${ }^{97}$ Matías de Novoa relató con profunda congoja aquel desastre militar: «Perdiose la honra de la nación y la reputación de España, porque no habiéndose hecho nada, el ejército comenzó a padecer hambre y a desacerse [...] venían por los caminos, así infantes como caballos, helados de el hambre, sin calor y sin fuerzas, cayéndose muertos por los caminos, y los que pudieron llegar a Zaragoza, en solos huesos y el pellejo, caían en los hospitales, y de allí, gastadas las mismas entrañas, sin poder tener espíritu, daban en la sepultura». ${ }^{98}$

La derrota y el desbarajuste no tenían paliativos y, según el mismo Matías de Novoa, dejaron a Felipe IV «macilento el rostro, caída la cabeza y con suspiros secretos».$^{99}$ Durante los dos meses siguientes, mientras se discutía sobre la conveniencia, o no, de que el rey permaneciese en Zaragoza, Olivares a pesar de estar personalmente y políticamente muy tocado, aún intentó explorar algunos medios para remontar aquella difícil situación. Como ocurría siempre después de un revés militar, el conde duque resucitó la vía de negociación con los catalanes. A mediados de noviembre de 1642 la Junta de Ejecución dispuso, con el visto bueno del monarca, que los marqueses de Leganés e Hinojosa, así como diversos prelados, tendiesen «a lo que se pudiere encaminar en Cataluña por vía de inteligencias», aunque ello siempre y cuando "se ofrecieran los catalanes»». ${ }^{100}$ Incluso después de los descalabros de aquellos infaustos meses de septiembre y octubre de 1642, para el conde duque la vía negociadora seguía siendo el último e indeseable camino para resolver la cuestión catalana; $y$, de hecho, lo planteaba al mismo tiempo que daba curso a una descabellada traza conspirativa para recuperar Catalunya.

\section{INTENTOS A LA DESESPERADA. UNA CONSPIRACIÓN PARA ALZAR EL CONDADO D'EMPÚRIES Y RECOBRAR CATALUNYA}

A mediados de octubre de 1642 hacia casi medio año que, aupado por el entusiasmo popular, Felipe IV había salido de Madrid en dirección al frente de Catalunya. Aquellos ánimos iniciales, sin embargo, se habían marchitado totalmente en los meses del estio y del inicio otoñal de 1642, pues ninguno de los objetivos de la jornada real se había cumplido y el balance militar sólo presentaba pérdidas y derrotas: Perpinyà y el resto de fortalezas del Rosselló habían caído en manos de los franceses; la armada

97. Sobre la batalla de Lleida ver SANABRE, Josep: La acción de Francia... (1956), p. 211 s., y también la informativa relación coetánea Relació compendiosa de tot lo que ha pasta desde que lo exercit del Rey de Castella parti de Tarragona y de la senyalada victoria que lo senyor mariscal de La Mothe ha guanyada a vista de la ciutat de Lleyda, Barcelona, 1642.

98. NovoA, Matías de: Historia de Felipe IV... (1886), p. 66 s.

99. Ibid., p. 67.

100. AGS, Guerra Antigua, 1420, Junta de Ejecución de 20 de noviembre de 1642. Anteriormente, el 19 de octubre, la misma Junta de Ejecución había recomendado no hacer públicas las resoluciones del Consejo de Aragón de declarar en forma judicial que los catalanes habían incurrido en crimen de Lesa Majestad. La Junta de Ejecución recomendaba que no se hiciese declaración alguna porqué «no es tiempo de hablar en esto», AGS, Guerra Antigua, 1420, Junta de Ejecución de 19 de octubre de 1642. 
española no había conseguido ocupar ninguna base portuaria en las costas catalanas, el ejército del marqués de Leganés había sido vencido por La Mothe en Lleida y, ahora, se iba deshaciendo irremediablemente, el descrédito de la Corona iba en aumento y la mayoría de nobles que a regañadientes habían acompañado a Aragón al monarca en aquella jornada, se manifestaban, más que nunca, abiertamente opuestos a Olivares y a sus formas de gobierno.

Es seguramente este contexto, en que el desanimo se mezclaba con la frustración y la impotencia, el que permite explicar porqué Felipe IV, Olivares y la Junta de Ejecución dieron crédito a otro plan descabellado para recuperar Catalunya, apostando por una conspiración que pretendía, a partir de un inicial alzamiento profelipista en el condado d'Empúries, retornar todo el Principado a la obediencia española.

El plan había sido ideado por Francesc Prim Desgüell i Despuig, caballero descendiente de una familia originaria de Besalú, ${ }^{101}$ quien al inicio del movimiento revolucionario catalán había sido designado por la junta de guerra maestre de campo de la veguería de Camprodón. ${ }^{102}$ Como otros miembros de la pequeña y mediana nobleza catalana, Desgüell, instalado en aquel momento en Castelló d'Empúries, se había ido distanciando de la alianza que había unido Cataluña a Francia. Aprovechando que un sobrino suyo, el capitán de caballería Pere Ferrer, estaba en la cercana fortaleza de Roses, aún bajo dominio español, Desgüell hizo llegar a su pariente una larga misiva en que proponía un plan para alzar el condado d'Empúries a favor del rey de España.

En esta carta, ${ }^{103}$ fechada en Castelló d'Empúries el día 30 de septiembre de 1642, Francisco Prim Desgüell daba cuenta, en primer lugar, de su situación personal. Este caballero catalán afirmaba que si no había abandonado formalmente el bando catalán era por «el pensar podía ser de más provecho aquí, en servicio de Su Majestad», dando a entender que había boicoteado o entorpecido la movilización que se le había encomendado, por parte de la junta de guerra catalana, de la veguería de Camprodon: «andube tan floxo que di mill ocasiones para que me quitasen el tercio». Además de estos motivos, Desgüell justificaba su permanencia en la Catalunya francesa por que de esta manera había protegido su hacienda y la de familiares que, como el mismo Pere Ferrer, habían iniciado el camino del exilio. Desgüell pedía su sobrino que trasladase su traza conspirativa al gobernador de Roses y, a través de éste, al rey Felipe IV, pero

101. Francesc Prim Desgüell i Despuig era hijo de Francesc Desgüell, caballero oriundo de Besalú, que había sido veguer de Girona, y de María Despuig, de una familia también noble de Girona. Hermano de Francesc era Pere Joan Desgüell i Despuig, abat de Sant Pere de Rodes. Ver MoRALES RocA, Francisco José: Próceres habilitados en las Cortes del Principado de Cataluña, siglo XVII, Madrid, 1983, 2 vols.

102. Francesc Prim Desgüell había sido nombrado maestre de campo de la veguería de Camprodon el noviembre de 1640; sin embargo, por la escasez de tropas de ese tercio de veguería, se dispuso su reforma ya a finales de ese mismo mes de noviembre. Desgüell recibió órdenes de Pau Claris de pasar a Figueres y ponerse bajo las órdenes de Francesc Tamarit. ACA, Generalitat G 116-1, fol. 100, Consell de Guerra. Posteriormente Desgüell fue nombrado gobernador del castillo de Salses.

103. AGS, Estado 2992, «Copia de carta escrita de Castelló de Ampurias al capitán Pedro Ferrer en 30 de septiembre de 1642. Para enviar a su Majestad con carta de 6 de octubre». La copia era ordenada y transmitida al rey por el príncipe Juan Carlos de Médicis. 
le encarecía que después de que se hubiese hecho una copia sin firma de la carta, esta fuese quemada, pues si caía en manos francocatalanas ello «fuera mi perdición».

Al iniciar el detalle de su plan, Desgüell dibujaba un contexto interno catalán muy favorable para que se produjese un alzamiento a favor del rey de España. Las poblaciones del Principado estaban cansadas tanto de la guerra como de la falta de justicia; los gravosos impuestos y el aumento de los precios de las subsistencias eran otros motivos de descontento, el cual llegaba hasta el punto que, según Desgüell, mucha gente proclamaba públicamente el deseo que «assí el rey de España nos quisiese perdonar y que volviésemos en el estado en que estávamos». Siguiendo esta descripción de la situación interna catalana, muchos naturales maldecían a los dirigentes que habían traído estas desgracias y se resistían también a cualquier movilización militar: «nadie quiere salir de sus casas». Este panorama llevaba a Desgüell a ver «buena ocasión para hacer nuestro negocio», concretando, a continuación, los pasos de su proyecto conspirativo:

1. En primer lugar, el rey de España debía enviar dinero a Roses para levantar una o dos compañías de caballería, que el propio Desgüell se encargaría de reclutar en el plazo máximo de quince días.

2. Esta recluta al servicio y con el dinero del rey de España, sería realizada de forma encubierta, pues Desgüell pediría una patente de capitán de caballos a la Junta del Batallón que en aquellos momentos era la responsable de la organización de la milicia catalana.

3. Con las compañías de caballería ya reclutadas y bajo su mando, Desgüell empezaría a promover motines contra los franceses, sirviéndose de dos personas «principales» de confianza que también eran favorables al rey de España. Estos agentes proespañoles esparcirían el rumor de que los franceses querrían despoblar las tierras del Principado de catalanes «y mudarlos a otro reyno», divulgando también que las autoridades galas proyectaban hacer levas de catalanes para Italia así como la confiscación de las haciendas «de algunas personas inútiles para la guerra».

4. El siguiente paso consistiría en que Francesc Prim Desgüell, haciéndose eco de estos rumores, proclamaría que no aceptaría tal traición de los franceses y que antes de que estos llevasen adelante sus siniestros planes contra los catalanes, él pediría perdón al rey de España.

5. Desgüell confiaba en realizar una pinza a las tropas francesas, las cuales se encontrarían entre los lugares y villas del condado d'Empúries que se sublevarían con el «arrimo de Roses» y una acción del ejército español en el frente de Aragón: «pondremos al francés en medio y le degollaremos toda la gente solo que su Majestad apriete de la parte de Lérida».

6. Para que el alzamiento proespañol se hiciese general, Desgüell proponía que Felipe IV enviase cien cartas de perdón para distribuir por las ciudades y villas de Catalunya (con el día y el año en blanco), así como veinte privilegios de nobleza y de ciudadanía honrada «para obligar mexor a algunos cavos» de dichas poblaciones. Actuación paralela a otras cartas que el conde de Perelada, la duquesa de Cardona i el marqués de Aitona habían, también, de hacer llegar a sus vasallos, alentándoles para alzarse a favor del rey de España. 
7. Finalmente, en su misiva, Desgüell preveía un sistema para comunicarse y coordinar sus acciones con el gobernador español de Roses. El noble catalán proponía que su respuesta al plan y las cartas de perdón y privilegios que pedía le fuesen dados en un escondrijo del mas Prats, cercano a Roses y a Castelló d'Empúries, sirviendo los disparos de la artillería de la fortaleza española para avisar a Desgüell de la entrega de los documentos escritos.

A finales de septiembre de 1642 la carta de Francisco Prim Desgüell llegó a manos de su sobrino Pere Ferrer y al príncipe Juan Carlos de Médicis, comandante de las galeras españolas. Desde Vinaroz, el 6 de octubre, el príncipe Juan Carlos envió a Felipe IV una copia de la carta de Desgüell, acompañada de un billete donde expresaba la opinión de que el plan del noble catalán le había parecido «negocio de consideración y no dificultoso de encaminar con vuena inteligencia». ${ }^{104}$ Un día después, y desde el puerto de Els Alfacs, el príncipe florentino también escribía a Olivares y al protonotario Jerónimo Villanueva informando que había encaminado a Pere Ferrer hacia Zaragoza, suplicando que se sirvieran «oyrle». ${ }^{105}$

El crédito que el comandante de la armada hispana otorgaba a la traza conspirativa de Desgüell era, sin duda, exagerado. Si bien es cierto que el sentimiento antifrancés crecía en Catalunya como consecuencia de las tropelías perpetradas por los ejércitos galos, era igualmente cierta la fuerza del sentimiento antiespañol por idénticos motivos. Por otro lado, el secreto y la sorpresa en que se fundamentaba el plan de Desgüell serían muy difíciles de mantener una vez se divulgasen las cartas de perdón del monarca español y también las enviadas por los nobles exiliados felipistas. Pero, lo que era más importante, una vez que los franceses ya se habían adueñado de todas las plazas fortificadas del Rosselló, un levantamiento armado en el vecino condado d'Empúries podía ser aplastado rápidamente.

Tal como hemos visto anteriormente, en esos mismos días en que el príncipe Juan Carlos escribía sus misivas, el ejército del marqués de Leganés era derrotado en las cercanías de Lleida por el mariscal La Mothe, haciendo así imposible cualquier operación de pinza contra los franceses. Aunque el descendiente de los grandes Médicis florentinos no conociese la noticia del descalabro de Lleida, su interés por alentar el plan de Desgüell es sospechoso. Muy probablemente el príncipe Juan Carlos quería desviar la atención de la Corte hacia esa empresa conspirativa pues tan sólo un día antes había excusado seguir las indicaciones de Felipe IV de conquistar o castigar algunas poblaciones del litoral catalán.

En una carta fechada el 19 de septiembre, Felipe IV había demandado al príncipe Juan Carlos que tipo de acciones podía desarrollar la flota de galeras para contribuir a la campaña de conquista de Catalunya y, en una comunicación posterior, el monarca ya proponía al almirante florentino que desembarcase en dos o tres poblaciones de la costa

104. AGS, Estado 2992, Juan Carlos de Médicis al rey, Vinaroz 6 de octubre de 1642.

105. AGS, Estado 2992, Juan Carlos de Médicis a Olivares y Jerónimo Villanueva, ambas fechadas el 7 de octubre de 1642 en el puerto de Els Alfacs 
entre Roses y Barcelona «y saqueasse y hiciesse todo el daño que pudiesse a su salvo, y que si pudiesse dar saco a alguno de los grandes sería de importacia», indicando que después volviese contra Vilanova de Sitges (Vilanova i la Geltrú) para después virar de nuevo hacia el norte y volver a castigar la costa entre Barcelona y Roses. Sin embargo, el príncipe Juan Carlos no estaba dispuesto a cumplir con esas indicaciones del monarca español. En una carta fechada en Vinaroz el día 5 de octubre, el almirante florentino comunicaba a Felipe IV que todos los capitanes veían en extremo dificultosa esa operación, pues decían que había «falta de todo» en las galeras, ello unido a la escasez de tropas (sólo contaban con un tercio napolitano muy disminuido y unas pocas milicias españolas y sicilianas) sólo permitiría saquear poblaciones menores, lo cual «sería de poca reputación», aconsejando el príncipe Juan Carlos a Felipe IV aplazar dicha acción marítima hasta la primavera del año siguiente. ${ }^{106}$

A través del príncipe Juan Carlos de Médicis, la propuesta de Desgüell, y también su sobrino Pere Ferrer, llegó a Zaragoza, donde fue objeto de atención por parte de la Junta de Ejecución. Con la presencia del conde duque de Olivares, el día 12 de octubre, la junta discutió la traza conspirativa propuesta por el noble catalán. Los miembros de la junta a pesar de ponderar que en la mayoría de los casos este tipo de proyectos acababan desbaratados y no tenían ningún efecto, decidieron apoyar el plan de Desgüell con el argumento de que tan solo con «un suceso que salga bien satisface cualesquiera otros que se hayan desvanecido y assí no se pueden menospreciar semejantes propuestas». ${ }^{107}$ En aquellos momentos, Olivares ya había perdido todas las bazas militares disponibles para actuar en el frente catalán y no tenía más remedio que confiar en un regalo de la diosa fortuna. Felipe IV dio el visto bueno a la propuesta de la Junta de Ejecución, escribiendo en el margen izquierdo de la consulta la lacónica fórmula «como parece».

En los días siguientes se prepararon las cédulas, títulos y cartas reales que había solicitado Desgüell para la ejecución de su plan. Se redactaron 100 cartas firmadas por Felipe IV destinadas a las villas y a las ciudades del Principado con un perdón real: «así con muy segura confianza de que havéis de recompensar en mi servicio el tiempo que havéis dexado de acudir a él, os perdono [...] pues de vuestra fineça i lealtad me persuado que solo la violencia i opresión de los malos os pudo tener en esta ceguedad». ${ }^{108}$ Asimismo, el rey expidió cédulas con 7 títulos de nobles, 7 de caballeros y 6 de ciudadanos honrados; igualmente se escribió al conde de Perelada para que alentase entre sus vasallos de l'Empordà el proyectado alzamiento proespañol; y también con fecha de 16 de octubre, el propio Felipe IV comunicaba a Desgüell la aceptación de su plan, dándole indicaciones para que el levantamiento de l'Empordà se iniciase con la ocupación de Castelló d'Empúries, «pues desto, sin duda, pende la mejor dirección de todo lo demás». ${ }^{109}$

106. AGS, Estado 2992, Juan Carlos de Médicis al rey, Vinaroz 5 de octubre de 1642.

107. AGS, Estado 2992, Junta de Ejecución de 12 de octubre de 1642.

108. En el borrador de dichas cartas se anota «fueron con fechas en blanco como se pidieron», AGS, Estado 2992.

109. AGS, Estado 2992, 16 de octubre de 1642. 
Al capitán Pere Ferrer se le entregaron todos los despachos junto a un código cifrado para las comunicaciones, con orden de que se encaminase al puerto de Vinaroz, donde una galera le estaría esperando para trasladarlo a Roses. ${ }^{110}$ Significativamente, también a comienzos de noviembre de 1642, el Consejo de Aragón resolvió cesar las ayudas de costa a los exiliados felipistas catalanes, ordenando que se les pagasen los atrasos y dándoles por adelantado cuatro mesadas, medida tomada el 9 de noviembre y refrendada el 22 de aquel mismo mes con ocasión de la «reducción de Barcelona». El motivo de esta consulta y de tales medidas era «el de la conveniencia que seria del servicio de su Majestad que todos los catalanes, que por su natural afecto se havían venido a los reales pies de su Majestad, volviesen a sus casas y residencias puesto que haviendo este número más de afectos conocidos en Barcelona y en el Principado, resultaría los buenos effectos que se desean en servicio de su Majestad». ${ }^{111}$

Todo este plan y sus preparativos quedó en nada, pues ni Castelló d'Empúries fue ocupado ni se produjo ningún movimiento profelipista en el condado d'Empúries. ${ }^{112}$ No sabemos las causas concretas que impidieron la ejecución de la traza conspirativa urdida por Francesc Prim Desgüell, aunque su falta de consistencia llevaba latente su fracaso y la derrota de Lleida anulaba cualquier posibilidad de echar fuera de Catalunya a los franceses. Sólo la desesperación del ministerio de Olivares permite entender la decisión de dar crédito y apoyo a un plan que, aparte de Desgüell, no tenía ningún otro soporte concreto. Sabemos que Francesc Desgüell se exilió de Catalunya el año siguiente, poniéndose bajo la protección de Felipe IV, ${ }^{113}$ del cual seguramente esperaba ser favorecido por la voluntad de servicio expresada en su traza conspirativa.

\section{¿UN FRACASO PERSONAL?}

Cuando el 6 de diciembre de 1642 el conde duque de Olivares entró en Madrid casi clandestinamente precedente del frente catalán, era un teniente general derrotado y un válido desprestigiado, que ni tan sólo la muerte de su gran rival, el cardenal Richelieu, acaecida en Paris dos días antes, podía salvar. El fracaso de la «jornada real» en tierras de la Corona de Aragón había sido de tal magnitud y había afectado

110. El día 29 de octubre, el príncipe Juan Carlos dio la orden desde Denia para que el capitán Pere Ferrer tuviese a su disposición una galera en el puerto de Vinaroz. AGS, Estado 2992 (copia de la orden).

111. ACA, Consejo de Aragón, leg. 253, consulta de 22 de noviembre de 1642.

112. No hemos encontrado ningún rastro de ello ni en las fuentes coetáneas ni en la bibliografía general o local empordanesa sobre la Guerra dels Segadors. El estudio más detallado sobre la Guerra dels Segadors en l'Empordà, continua siendo el de SANABRE, Josep: La Guerra dels Segadors en el Ampurdán y la actuación de la casa condal de Peralada, Perelada, 1955, que nada dice de este episodio.

113. Francesc Prim Desgüell aparece en la nómina de exiliados catalanes felipistas elaborada por VIDAL PLA, Jordi: Guerra dels Segadors i crisi social, Barcelona, 1984, apéndice 1. También sabemos que a comienzos del año 1645, Desgüell solicitó al rey que se reconcediese la capitanía de la compañía de caballos de Roses que hasta aquel momento había tenido a su cargo Juan de Bustamante, argumentando que en Roses tenía a su mujer y a sus hijos desterrados de los catalanes. El Consejo de Aragón informó favorablemente sobre la petición de Desgüell por «lo que ha obrado en Cataluña al servicio de su Majestad», ACA, Consejo de Aragón, leg. 253, consulta de 9 de marzo de 1645. 
tan directamente a la reputación de Felipe IV que la destitución del válido que la había impulsado y planificado era poco menos que inevitable. En aquellos días invernales, sabedores de la debilidad del conde duque, sus numerosos enemigos en la Corte hicieron ostentación de su animadversión y oposición hacia el privado del rey. De nuevo, Madrid quedó inundado de pasquines satíricos que cuartearon inmisericordemente la figura de Olivares y también la del rey. Uno de estos escritos, La tala de los Olivares, anunciaba ya la suerte del hasta entonces todopoderoso privado:

«Al retiro de su huerto vuelve el rey desengañado, que aunque digáis yo he pecado dará vuestro mal gobierno otro Judas al infierno y a España un conde ahorcado». ${ }^{114}$

Significativamente, por aquellas mismas fechas, Olivares sufría una importante desautorización real. Cuando el 22 de diciembre de 1642 los once miembros del Consejo de Estado trataron, una vez más, sobre que frente peninsular debía de ser prioritario en los esfuerzos bélicos de la monarquía, a pesar de que ocho miembros del Consejo encabezados por el conde-duque de Olivares apostasen por un cambio de estrategia, recomendando iniciar una guerra ofensiva en el frente luso, Felipe IV impuso el criterio de supeditar Portugal a Cataluña. Y, posteriormente, en otra reunión del Consejo de Estado de 30 de enero de 1643 -una vez ya descabalgado políticamente Olivares-, los miembros del Consejo, ahora de forma unánime, trazaron los planes de la futura campaña militar de Cataluña para 1643, la cual tenía que absorber la máxima atención y recursos. ${ }^{115}$

Finalmente, como es sabido, el 17 de enero de 1643, Felipe IV comunicó a Olivares que había decidido aceptar sus reiteradas peticiones de retirarse de la gobernación política de la monarquía. ${ }^{116}$

Tal como ya dijimos, si bien la desastrada campaña de Cataluña no fue la única causa de la caída del conde duque, si que fue el elemento final determinante, y por ello el análisis de los criterios político-militares con que fue planificada y conducida dicha acción tiene una especial relevancia.

114. Reproducido por EGIDO, Teófanes «La sátira política arma de la oposición a Olivares» en ELLIOTT John H. y GARCía SANZ, A. (Eds.): La España del conde duque de Olivares, Valladolid, 1990, p. 339-372, la cita en p. 362.

115. Ver CAMARERO, Raquel: «La Guerra de Recuperación de Cataluña y la necesidad de establecer prioridades en la Monarquía Hispánica (1640-1643)» en GARCía Hernán, E. y MAFFI, D. (Eds.): Guerra y sociedad en la Monarquía Hispana, Madrid, 2006, vol. I, p. 323-357.

116. Sobre la caída de Olivares, básicamente MARAÑON, Gregorio: El conde duque de Olivares... (1980), p. 331 ss.; Elliott, John H.: El conde duque... (1990), p. 619 ss.; del mismo autor, «El programa de Olivares y los movimientos de 1640» en la Historia de España Ramón Menéndez Pidal, vol. XXV, Madrid, 1982, p. 497 ss.; Benigno, Francesco: La sombra del rey, Madrid, 1992, p. 197 ss.; y StradLInG, R.A.: Felipe IV y el gobierno de España 1621-1665, Madrid, 1989, p. 303 ss. 
La campaña del frente catalán de 1642 fue impulsada por el propio conde duque tras el éxito del socorro de Tarragona en agosto de 1641, siendo concebida como una acción militar destinada a reparar el desprestigio y los negativos efectos políticos y militares derivados de la fallida expedición de castigo dirigida por el marqués de Los Vélez. Hasta aquel momento, según coinciden diversos observadores, Olivares había desestimado todas las opciones negociadoras ventajosas que, para resolver el contencioso con los catalanes, se le habían presentado; ello por estar convencido de que una «rebelión formada» como la de Catalunya debía ser aplastada de una manera ejemplar, pues sino quedaría dañada la reputación del monarca y la suya propia. Además, después del triunfo de Tarragona, Olivares también pensaba contar con suficientes bazas políticas, militares y financieras para salir triunfante de aquella apuesta: capacidad de reunir un ejército de unas dimensiones parecidas al conducido un año atrás por el marqués de Los Vélez, dominio del frente marítimo, llegada de cuantiosas cantidades de plata de las Indias por los atrasos pendientes, crecientes disensiones internas en el bando francocatalan y esperanzas de que la aristocracia francesa enemiga de Richelieu diese un tumbo a la situación política de la monarquía gala.

Aunque existiesen bases reales para sostener algunas de estas convicciones o esperanzas futuras, no cabe duda que en la actitud del conde duque, de muchos ministros cortesanos y, también, del propio Felipe IV, había un exceso de confianza que rayaba con la prepotencia y la soberbia. Llama la atención de la documentación manejada correspondiente a las juntas y consejos del gobierno central, la casi total falta de atención a las acciones y respuestas que por parte catalana y francesa se podían dar a las iniciativas planificadas por el ministerio de Olivares, así como la inexistencia de una lectura crítica a las directrices políticas y militares anteriores que habían acabado fracasando, y también una desatención a las causas de fondo que habían propiciado el alzamiento catalán.

Este unilateralismo con que, desde la Corte de Madrid, se leía el escenario político-militar propiciaba, por un lado, una percepción exagerada de la voluntad de los catalanes a volver sin condiciones al dominio de su «legítimo» rey y señor, olvidando el creciente odio anticastellano de amplias capas de la población del Principado y Condados, consecuencia del comportamiento sanguinario de los ejércitos hispanos que invadían o ocupaban Catalunya. Tampoco no se hacía previsión de la respuesta francesa a la «jornada real» de Felipe IV, y, como es sabido, Luis XIII y Richelieu reaccionaron con la venida del Rey Cristianísimo al frente catalán, participando en la victoriosa toma de Perpinyà. Asimismo, acciones militares concretas, como la alocada cabalgada del marqués de Povar para el socorro del Rosselló, obviaron los más elementales cálculos de las adversidades a que podían enfrentarse.

Pero, sobre todo, esta visión unilateral y en buena medida prepotente de aquel conflicto abierto en el «continente» de España, restringía enormemente sus vías de solución, pues tanto para Olivares como para Felipe IV, sólo desde una posición de superioridad basada en la fuerza de las armas era posible y recomendable resolverlo. Las distintas opciones negociadores no habían llegado a buen puerto porqué sólo eran contempladas como una fase que debía concretar una posición de dominio y sujeción 
previos, o como un expediente a explorar cuando las adversidades militares enflaquecían la vía de la conquista.

Sin embargo, no creo que estas convicciones políticas unilateralistas tuviesen en Olivares y Felipe IV a sus únicos responsables y seguidores, ni tampoco que fuesen solamente fruto de un choque político coyuntural. Las bases ideológicas en que se sustentaba el proyecto del estado moderno español, ya madurado en la teoría política por la intelligentsia castellano cortesana a finales del siglo XVI e inicios del XVII, se fundamentaban en una cultura política en que además de los valores del rey y la religión, incorporaba a otros que pasaban por la unidad de una patria española asentada en los territorios de la antigua Hispania y por un poder político de tendencias absolutistas. ${ }^{117}$ Los ideales de un estado territorialmente compacto y institucionalmente unido, culminado por un poder real fuerte impregnan la lógica política del gobierno central de la monarquía española en el siglo XVII y apuntan a un modelo de estado unitarista, autoritario y unilateralmente concebido para el ámbito hispánico. Estos ideales legitimarían el uso de la coerción para vencer las resistencias de las otras formaciones históricas peninsulares que, con tradiciones políticas propias y diferenciadas, se opusieron a este modelo estatal elaborado desde el centro castellanocortesano.

117. Ver el que ya he expuesto al respecto en Construccions politiques i identitats nacionals. Catalunya i els orígens de l'estat modern espanyol, Barcelona, 2005, especialmente p. 53-134. 